28 Resarch Square

\title{
Genome-Wide Identification and Expression Profiling Analysis of WOX Family Proteins Encoded Genes in Triticeae Plant Species
}

\section{Lei Shi}

Chinese Academy of Agricultural Sciences Institute of Crop Sciences

\section{Ke Wang}

Chinese Academy of Agricultural Sciences Institute of Crop Sciences

\section{Lipu Du}

Chinese Academy of Agricultural Sciences Institute of Crop Sciences

\section{Yuxia Song}

Key Laboratory of Agricultural Biotechnology of Ningxia, Ningxia Academy of Agriculture and Forestry Sciences

Huihui Li

Chinese Academy of Agricultural Sciences Institute of Crop Sciences

Xingguo Ye ( $\nabla$ yexingguo@caas.cn )

Chinese Academy of Agricultural Sciences Institute of Crop Sciences https://orcid.org/0000-0002-6616-2753

\section{Research article}

Keywords: Triticeae plant species, WUSCHEL-related homeobox, Chromosomal location, Phylogenetic analysis, Differential expression

Posted Date: October 1st, 2020

DOI: https://doi.org/10.21203/rs.3.rs-73136/v1

License: @ (i) This work is licensed under a Creative Commons Attribution 4.0 International License. Read Full License 


\section{Abstract}

Background: Genotype dependence of plant regeneration is an important factor restricting the genetic improvement of Triticeae plant species. The WUSCHEL-related homeobox (WOX) is a group of plant specific transcription factor, which play an important role in plant growth and development, and cell division and differentiation. Recent studies revealed that the application of regeneration-related genes such as WOX and BABY BOOM (BBM) could improve plant regeneration. The application of WOX genes is one of the ways to improve the genetic transformation system of Triticeae and other species, but there are rare studies in this area.

Results: From the available genome sequence database, in total 136 WOX transcripts were identified for the Triticeae plants, including 43 in Triticum aestivum, 30 in Triticum turgidum, 25 in Triticum dicoccoides, 17 in Hordeum vulgare, 13 in Aegilops tauschii, and 8 in Triticum urartu. All of the WOX family genes were distributed on the chromosomes of homologous groups 1 to 5 in the six Triticeae species, part of which were confirmed by their specific PCR markers using a set of $T$. durum- T. aestivum genome $D$ substitution lines. All of the WOX proteins in the six Triticeae species could be grouped into three clades, similar to those in rice (Oryza sativa L.) and Arabidopsis. WOX family members were conserved among these Triticeae plants, all of them contained the conserved HOX DNA-binding homeodomain, and WUS clade members contained the characteristic WUS motif, while only TaWUS and TaWOX9 in all the six Triticeae plant species contained the ERF-associated amphiphilic repression (EAR) motif. The expression profiles of TaWOX genes by quantitative real-time PCR (qPCR) showed obvious difference among WOX family members.

Conclusions: Totally 130 WOX genes were identified in the six Triticeae plant species. The WOX family genes were located on the chromosomes in the five homologous groups except groups 6 and 7 in the Triticeae species, and their expression profiles were different in different tissues, indicating that each of them had diverse function. The findings in this study could provide a basis for evolution and functional investigation and practical application of the WOX family genes in Triticeae plant species.

\section{Background}

Triticeae tribe belongs to the Poaceae family, and is made up of more than 350 plant species in 30 genera around. In Triticeae plants, a series of species such as Triticum aestivum (bread wheat), Hordeum vulgare (barley), Secale cereale (rye), Triticum urartu, Triticum dicoccoides, and Triticum turgidum have been cultivated as crops and provides necessary nutrition for more than two billion people in the world [1, 2]. For a long time, people are interested in understanding the origination, genetic basis and evolution of Triticeae plants for their better improvement. Clear interpretation on genetic information of Triticeae plants may bring us closer to achieve the aforementioned objective. The assembling of wheat genome is a milestone in interpreting the genetic information of Triticeae plants. However, due to the large genome size of up to $16 \mathrm{~Gb}$, the genomic study on wheat is legged behind of rice and maize [3]. The application of modern biotechnology tools such as transgene and gene editing in plant breeding can help us to increase yield, improve quality, and enhance biotic or abiotic resistance of major crops, but the realization of these aims depends on genetic transformation. The ability of regenerating new plantlets from in vitro tissues is a big limitation that restricts the application of genetic transformation and gene editing systems $[4,5]$.

Regeneration ability is one of important genetically physiological traits for most plants, which enables plants recover from wound tissues and form new organs. For modifying plants using genetic-engineering strategy, shoot or somatic embryo production from isolated tissues or cells is an indispensable step to achieve transgenic plants. But, it is still difficult to obtain regenerated plants in the process of genetic transformation from most genotypes (especially the extensively commercial varieties) of wheat and other Triticeae species [5-7]. During plant regeneration, a series of genes express in an orderly manner under the regulation of auxin and cytokinin. These regeneration-related genes

Page 2/25 
include WUSCHEL-RELATED HOMEOBOX (WOX), AUXIN RESPONSE FACTOR (ARF), BABY BOOM (BBM), SCARECROW (SCR), SHORT ROOT (SHR), PLETHORA (PLT), CUP-SHAPED COTYLEDON (CUC), and YUCCA (YUC), which express during the progress of embryonic patterning, somatic embryogenesis, cell differentiation, wound reparation, and epigenetic reprogramming [5,8-12]. An in-depth understanding of regeneration-related genes in molecular level will make it possible to break through the bottleneck in genetic transformation and build a more efficient transformation system with less genotype-dependent. The application of regeneration-associated genes including WUS2 and BBM in crop transformation has achieved a great success, by which various maize inbred lines and tissues, and recalcitrant genotypes of Indica rice, sugarcane, and sorghum can be efficiently transformed for getting transgenic plants [13, 14].

The WOX family is a group of plant specific transcription factors and belongs to the homeobox (HB) transcription factor family [15]. All the identified WOX genes contain a conserved sequence of amino acids (60-66 residues), which is called as homeodomain (HD) encoded by the HB DNA sequence $[16,17]$. The distinctive WUS-box motif forms as T-L-X-L-F-P-X$X(T-L-[D E Q P]-L-F-P-[G I T V L]-[G S K N T C V])$, of which the consensus structure is TLELFPLH [15]. These homolog sequences fold into a DNA-binding domain. Update published data suggests that WOX genes act as pivotal regulators during the progress of embryonic development and polarization, plant growth and development, stem cell differentiation, embryo patterning, and flower development [18-22]. There are 15 WOX genes in Arabidopsis thaliana, 13 in rice, and 21 in maize [15, 23, 24]. In Arabidopsis, as a stem cell regulator, AtWUS expresses in the organizing-center (OC) cells in the shoot apical meristem and regulates plant growth and shoot stem cell maintaining $[25,26]$. Ectopic overexpression of WUS genes promotes cell dedifferentiation in shoot meristem, somatic embryo formation, adventitious shoot and lateral leaf origination [26-28].

It is found that AtWOX1 possibly regulates the activity of S-adenosylmethionine decarboxylase polyamine homeostasis and/or the expression of CLAVATA3(CLV3), and has an important function in meristem development in Arabidopsis. Overexpression of AtWOX1 leads to abnormal meristem development and polyamine homeostasis [29]. Normally, AtWOX2 expresses in the zygote and early embryogenesis formation, and performs functions in correcting the apical domain development of the embryos [23]. AtWOX2 triggers the expression of PINFORMED1 (PIN1), which is an auxin transport and localizes auxin to the cotyledonary tips of early embryo and root pole [18]. AtWOX3 (PRESSED FLOWER1, $P R S 1)$ expresses in the peripheral layer of shoot meristem and regulates cells to form the lateral domain in vegetative and floral organs [30]. The expression of AtWOX2 and AtWOX3 are regulated by Leafy Cotyledon2 (LEC2), and AtWOX2 and AtWOX3 play essential roles in somatic embryogenesis [31]. AtWOX4 expresses in a narrow domain in cambial cells, and AtWOX4 coordinating with PHLOEM INTERCALATED WITH XYLEM (PXY) acts as a key regulator for cambium activity in the main stem [32]. AtWOX5 expresses in the QC of meristematic zone in root tips, regulates the columella stem cell (CSC) identity, and helps to maintain the root stem cell niche [33]. AtWOX6 (PRETTY FEW SEEDS2, PFS2) expresses in developing ovules and primordials and differentiating organs, regulates ovule development, and affects differentiation and maturation of leaves, outer integuments and floral primordial [34]. AtWOX7 expresses during all development stages of lateral root, but primarily involves in the initiation of lateral root [35]. AtWOX8 (STIMPY-LIKE) and AtWOX9 (STIMPY) are closely homologs $[36,37]$ and responsible for maintaining the normal development of both basal and apical embryo lineages at early development stage [18]. The expression of AtWOX8 is induced by AtWRKY2 in the basal cell lineage at the initiation stage of embryogenesis [38]. AtWOX11 plays a key role in the course of vascular cambium differentiation to new lateral root founder cells. AtWOX11 is strongly induced expressed in de novo root organogenesis, which is the same as its homologous AtWOX12 [39, 40]. AtWOX13 expresses mainly in meristematic tissues to promote replum development and orchestrate fruit patterning [41]. AtWOX14 is regulated by the CLAVATA3/ESRLIKE41/PHLOEM INTERCALATED WITH XYLEM (CLE41/PXY) pair, expresses in the procambium during stem maturation, and promotes xylem differentiation, vascular cell differentiation and lignification in inflorescence stems $[42,43]$. 
Based on the phylogenetic analysis in Arabidopsis, plant WOX proteins are naturally divided into three clades: WUS and WOX1 to WOX7 in the WUS clade; WOX8, 9, 11, and 12 in the intermediate clade; and WOX10, 13, and 14 in the ancient clade [15]. But, the WOX genes in Triticeae plant species have not been fully identified and characterized yet. Therefore, the objectives of this study are, (1) identifying WOX genes in the six Triticeae plant species including T. aestivum, T. turgidum, T. dicoccoides, H. vulgare, A. tauschii, and T. urartu, and aligning them onto chromosomes; (2) dividing all of the WOX proteins in the six Triticeae species into groups by phylogenetic analysis using deduced protein sequences from all the WOX genes and the sequences of OsWOX genes from rice and AtWOX genes from Arabidopsis; and (3) analyzing the differential expression of TaWOX genes in different tissues by RNA sequencing (RNA-seq) and quantitative real-time PCR (qPCR). Our results would provide insights for further understanding the functions and evolution clarification of WOX family genes in Triticeae plants, and facilitate their application in gene transformation for the improvement of Triticeae plants.

\section{Results}

\section{Identification of WOX genes in Triticeae plant species}

Totally, 43 TaWOX transcripts were obtained using the recently released IWGSC wheat genome [3], and there were still 6 pseudo gene copies (Table 1). Specifically, 15 WOX transcripts in H. vulgare (Table 2), 13 WOX transcripts in A. tauschii (Table S1), 23 WOX transcripts in T. dicoccoides (Table S2), 28 WOX transcripts in T. turgidum (Table S3), and 8 WOX transcripts in T. urartu (Table S4) were identified from IWGSC genome database, respectively. Some homologous alleles of WOX genes were not annotated as transcripts in the database, but were also collected and listed in the tables. For example, TaWUSb and TaWUSd were located on chromosomes 2B and 2D in T. aestivum, respectively (Table 1). The WUS genes in other five Triticeae plant species were also located on their group 2 chromosomes (Table 2, Table S1-S4). TdWOX12a, TdWOX12b, TdWOX7b and TdWOX13b were located on chromosomes 1A, 1B, and 3B in T. dicoccoides, respectively (Table $\mathrm{S} 2$ ). 
Table 1

Characteristics of TaWOX gene family members in T. aestivum.

\begin{tabular}{|c|c|c|c|c|c|c|}
\hline Gene & Gene locus & Chromosome & $\begin{array}{l}\text { Gene stretch } \\
\text { region }\end{array}$ & $\begin{array}{l}\text { mRNA } \\
\text { length } \\
\text { (bp) }\end{array}$ & $\begin{array}{l}\text { Protein } \\
\text { Sequence } \\
\text { Length } \\
\text { (aa) }\end{array}$ & UniProt ID \\
\hline TaWOX2a & TraesCS1A02G052000 & $1 \mathrm{~A}$ & $\begin{array}{l}33,397,501- \\
33,398,955:-1\end{array}$ & 1314 & 263 & A0A1D5S1T3 \\
\hline TaWOX12a & TraesCS1A02G399400 & $1 \mathrm{~A}$ & $\begin{array}{l}563,818,671- \\
563,823,103: 1\end{array}$ & 1854 & 486 & A0A1D5RPD4 \\
\hline TaWOX2b & TraesCS1B02G069000 & $1 \mathrm{~B}$ & $\begin{array}{l}53,364,615- \\
53,365,864:-1\end{array}$ & 1119 & 264 & $\begin{array}{l}\text { A0A1B1XWM5 } \\
\text { A0A1B1XWM7 } \\
\text { W5ABB5 }\end{array}$ \\
\hline TaWOX12b & TraesCS1B02G427400 & $1 \mathrm{~B}$ & $\begin{array}{l}652,781,930- \\
652,786,496: 1\end{array}$ & 1983 & 485 & A0A1D5SDQ8 \\
\hline TaWoX2d & TraesCS1D02G054000 & $1 \mathrm{D}$ & $\begin{array}{l}35,059,826- \\
35,061,088:-1\end{array}$ & 1138 & 267 & W5ANF9 \\
\hline TaWOX12d & TraesCS1D02G406900 & $1 \mathrm{D}$ & $\begin{array}{l}470,219,711- \\
470,224,514: 1\end{array}$ & 2028 & 486 & A0A1D5SWV6 \\
\hline TaWUS & TraesCS2A02G491900 & $2 \mathrm{~A}$ & $\begin{array}{l}724,513,458- \\
724,514,647: 1\end{array}$ & 927 & 308 & A0A1D5TC72 \\
\hline TaWoX4a & TraesCS2A02G514000 & $2 \mathrm{~A}$ & $\begin{array}{l}738,371,677- \\
738,372,966: 1\end{array}$ & 1061 & 234 & A0A1D5TF70 \\
\hline TaWOX11a & TraesCS2A02G100700 & $2 \mathrm{~A}$ & $\begin{array}{l}53,782,606- \\
53,785,288: 1\end{array}$ & 1380 & 265 & A0A1D5TJV0 \\
\hline TaWOX11b & TraesCS2B02G117900 & $2 B$ & $\begin{array}{l}81,755,546- \\
81,758,516: 1\end{array}$ & 1366 & 261 & A0A1D5U6K9 \\
\hline TaWOX4b & TraesCS2B02G542600 & $2 B$ & $\begin{array}{l}740,320,190- \\
740,321,561:-1\end{array}$ & 1002 & 237 & W5BBK8 \\
\hline TaWOX11d & TraesCS2D02G100200 & $2 \mathrm{D}$ & $\begin{array}{l}52,227,203- \\
52,229,885: 1\end{array}$ & 1379 & 264 & $\begin{array}{l}\text { A0A1D5TJV1 } \\
\text { A0A1D5V0E6 }\end{array}$ \\
\hline \multirow[t]{2}{*}{ TaWOX4d } & TraesCS2D02G515600 & $2 \mathrm{D}$ & $\begin{array}{l}606,709,221- \\
606,710,431: 1\end{array}$ & 979 & 237 & A0A1D5UH04 \\
\hline & & $2 \mathrm{D}$ & $\begin{array}{l}\text { 590146287- } \\
\text { 590147498:1 }\end{array}$ & & & \\
\hline TaWOX10a & TraesCS3A02G073500 & $3 A$ & $\begin{array}{l}45,776,166- \\
45,777,448: 1\end{array}$ & 992 & 260 & A0A1D5VKG7 \\
\hline TaWoX7a & TraesCS3A02G247200 & $3 A$ & $\begin{array}{l}465,225,214- \\
465,228,773: 1\end{array}$ & 1968 & 515 & A0A1D5V4S9 \\
\hline TaWoX8a & TraesCS3A02G341700 & $3 A$ & $\begin{array}{l}588,932,808- \\
588,937,056: 1\end{array}$ & 2230 & 265 & $\begin{array}{l}\text { A0A077RTA5 } \\
\text { A0A1D5VD81 } \\
\text { A0A1D5VQY0 } \\
\text { A0A1D5WIZ6 } \\
\text { A0A1D6RQB3 } \\
\text { A0A1D6RQB4 } \\
\text { A0A1D6RQB5 } \\
\text { W5CGX8 }\end{array}$ \\
\hline
\end{tabular}




\begin{tabular}{|c|c|c|c|c|c|c|}
\hline Gene & Gene locus & Chromosome & $\begin{array}{l}\text { Gene stretch } \\
\text { region }\end{array}$ & $\begin{array}{l}\text { mRNA } \\
\text { length } \\
\text { (bp) }\end{array}$ & $\begin{array}{l}\text { Protein } \\
\text { Sequence } \\
\text { Length } \\
\text { (aa) }\end{array}$ & UniProt ID \\
\hline TaWoX14.1a & TraesCS3A02G358200 & $3 \mathrm{~A}$ & $\begin{array}{l}606,515,981- \\
606,519,197:-1\end{array}$ & 1162 & 288 & A0A1D5VFV1 \\
\hline TaWOX13a & TraesCS3A02G358100 & $3 \mathrm{~A}$ & $\begin{array}{l}606,444,775- \\
606,446,830:-1\end{array}$ & 1138 & 301 & A0A1D5VA42 \\
\hline TaWoX14.2a & TraesCS3A02G358400 & $3 \mathrm{~A}$ & $\begin{array}{l}606,573,438- \\
606,576,220:-1\end{array}$ & 1133 & 290 & A0A1D6RQ92 \\
\hline TaWOX9a & TraesCS3A02G368100 & $3 A$ & $\begin{array}{l}617,060,395- \\
617,061,453:-1\end{array}$ & 949 & 212 & T1WFN3 \\
\hline TaWOX10b & TraesCS3B02G087800 & $3 B$ & $\begin{array}{l}56,055,903- \\
56,057,760:-1\end{array}$ & 1196 & 261 & A0A1D5VWS6 \\
\hline TaWOX7b & TraesCS3B02G272200 & $3 B$ & $\begin{array}{l}438,378,936- \\
438,382,259:-1\end{array}$ & 1776 & 515 & A0A077RSZ6 \\
\hline TaWoX8b & TraesCS3B02G373800 & 3B & $\begin{array}{l}586,694,870- \\
586,698,391: 1\end{array}$ & 1216 & 261 & $\begin{array}{l}\text { A0A077S168 } \\
\text { A0A1D 5WT92 }\end{array}$ \\
\hline TaWOX13b & TraesCS3B02G391100 & 3B & $\begin{array}{l}616,425,121- \\
616,426,978:-1\end{array}$ & 900 & 299 & A0A1D5VST7 \\
\hline TaWOX14b & TraesCS3B02G391200 & 3B & $\begin{array}{l}\text { 616,645,332- } \\
616,647,892:-1\end{array}$ & 1216 & 290 & A0A1D5WB93 \\
\hline TaWOX9b & TraesCS3B02G399800 & $3 B$ & $\begin{array}{l}631,036,656- \\
631,037,718:-1\end{array}$ & 948 & 209 & D8L9N7 \\
\hline TaWoX10d & TraesCS3D02G073300 & $3 \mathrm{D}$ & $\begin{array}{l}33,294,918- \\
33,295,992: 1\end{array}$ & 786 & 261 & $\begin{array}{l}\text { A0A077RHG9 } \\
\text { A0A1D5WSB5 } \\
\text { A0A341T564 }\end{array}$ \\
\hline TaWOX7d & TraesCS3D02G244300 & 3D & $\begin{array}{l}339,473,290- \\
339,476,679:-1\end{array}$ & 1834 & 513 & A0A1D5WHW6 \\
\hline TaWOX8d & TraesCS3D02G335500 & 3D & $\begin{array}{l}447,560,283- \\
447,562,999: 1\end{array}$ & 792 & 263 & $\begin{array}{l}\text { A0A1D5VD82 } \\
\text { A0A341TAX4 }\end{array}$ \\
\hline TaWOX13d & TraesCS3D02G352500 & $3 \mathrm{D}$ & $\begin{array}{l}463,197,196- \\
463,199,275:-1\end{array}$ & 1112 & 298 & A0A1D5WMN9 \\
\hline TaWOX14.1d & TraesCS3D02G352600 & 3D & $\begin{array}{l}463,227,796- \\
463,230,501:-1\end{array}$ & 895 & 285 & A0A1D5WPP9 \\
\hline TaWOX14.2d & TraesCS3D02G352700 & $3 \mathrm{D}$ & $\begin{array}{l}463,378,560- \\
463,381,808:-1\end{array}$ & 942 & 291 & A0A1D5WNX7 \\
\hline TaWoX9d & TraesCS3D02G361100 & $3 \mathrm{D}$ & $\begin{array}{l}474,614,857- \\
474,615,873:-1\end{array}$ & 901 & 210 & T1WGQ3 \\
\hline TaWoX6a & TraesCS4A02G130200 & $4 \mathrm{~A}$ & $\begin{array}{l}170,708,103- \\
170,711,065:-1\end{array}$ & 1350 & 307 & A0A341TSN5 \\
\hline TaWoX6b & TraesCS4B02G174400 & $4 \mathrm{~B}$ & $\begin{array}{l}382,691,977- \\
382,694,806: 1\end{array}$ & 1254 & 309 & $\begin{array}{l}\text { AOA1D5XNI6 } \\
\text { A0A1D5YYYY9 }\end{array}$ \\
\hline TaWoX6d & TraesCS4D02G176400 & $4 \mathrm{D}$ & $\begin{array}{l}306,795,298- \\
306,798,208: 1\end{array}$ & 1262 & 306 & A0A341UK30 \\
\hline
\end{tabular}




\begin{tabular}{|c|c|c|c|c|c|c|}
\hline Gene & Gene locus & Chromosome & $\begin{array}{l}\text { Gene stretch } \\
\text { region }\end{array}$ & $\begin{array}{l}\text { mRNA } \\
\text { length } \\
\text { (bp) }\end{array}$ & $\begin{array}{l}\text { Protein } \\
\text { Sequence } \\
\text { Length } \\
\text { (aa) }\end{array}$ & UniProt ID \\
\hline TaWOX5a & TraesCS5A02G085000 & $5 \mathrm{~A}$ & $\begin{array}{l}111,588,730- \\
111,590,895: 1\end{array}$ & 1220 & 318 & A0A341UT17 \\
\hline TaWOX3a & TraesCS5A02G157300 & $5 \mathrm{~A}$ & $\begin{array}{l}336,949,988- \\
336,951,183: 1\end{array}$ & 1060 & 241 & A0A1D5YD57 \\
\hline TaWOX5b & TraesCS5B02G091000 & $5 B$ & $\begin{array}{l}118,451,983- \\
118,454,221: 1\end{array}$ & 1302 & 321 & $\begin{array}{l}\text { A0A1D5ZG91 } \\
\text { A0A1D6A0K9 }\end{array}$ \\
\hline TaWOX3b & TraesCS5B02G156400 & $5 B$ & $\begin{array}{l}288,891,901- \\
288,893,003:-1\end{array}$ & 968 & 241 & W5F9A2 \\
\hline TaWOX5d & TraesCS5D02G097400 & $5 \mathrm{D}$ & $\begin{array}{l}108,103,399- \\
108,105,722: 1\end{array}$ & 1381 & 322 & W0Z680 \\
\hline TaWoX3d & TraesCS5D02G162600 & $5 \mathrm{D}$ & $\begin{array}{l}254,023,305- \\
254,024,410: 1\end{array}$ & 1006 & 242 & W5FQU4 \\
\hline TaWOX8u & TraesCSU02G204800 & Un & $\begin{array}{l}304,503,012- \\
304,503,827: 1\end{array}$ & 617 & 156 & $\begin{array}{l}\text { A0A077RQB3 } \\
\text { A0A096UQ47 } \\
\text { A0A1D6RTL8 } \\
\text { A0A1D6RTL9 }\end{array}$ \\
\hline TaWUSb & & $2 B$ & $\begin{array}{l}714,777,526- \\
714,778,733: 1\end{array}$ & 921 & 306 & \\
\hline \multirow[t]{7}{*}{ TaWUSd } & & $2 \mathrm{D}$ & $\begin{array}{l}590,146,287- \\
590,147,498: 1\end{array}$ & 927 & 308 & \\
\hline & & $1 \mathrm{D}$ & $\begin{array}{l}6,219,571- \\
6,220,231: 1\end{array}$ & & & \\
\hline & & $3 \mathrm{~A}$ & $\begin{array}{l}64,319,914- \\
64,325,218:-1\end{array}$ & & & \\
\hline & & $3 B$ & $\begin{array}{l}83,465,544- \\
83,470,232:-1\end{array}$ & & & \\
\hline & & $3 B$ & $\begin{array}{l}83,471,253- \\
83,471,941:-1\end{array}$ & & & \\
\hline & & $3 D$ & $\begin{array}{l}52,801,752- \\
52,812,298:-1\end{array}$ & & & \\
\hline & & $3 D$ & $\begin{array}{l}463,261,309- \\
463,261,744:-1\end{array}$ & & & \\
\hline
\end{tabular}


Table 2

Characteristics of HvWOX gene family members in $H$. vulgare

\begin{tabular}{|c|c|c|c|c|c|c|}
\hline Gene & Gene locus & Chromosome & $\begin{array}{l}\text { Gene stretch } \\
\text { region }\end{array}$ & $\begin{array}{l}\text { mRNA } \\
\text { length } \\
\text { (bp) }\end{array}$ & $\begin{array}{l}\text { Protein } \\
\text { Sequence } \\
\text { Length } \\
\text { (aa) }\end{array}$ & Uniprot ID \\
\hline HvWOX2 & HORVU1Hr1G010580 & $1 \mathrm{H}$ & $\begin{array}{l}24,444,001- \\
24,445,742: 1\end{array}$ & 1742 & 279 & A0A287ELV0 \\
\hline \multirow[t]{2}{*}{ HvWOX12 } & \multirow[t]{2}{*}{ HORVU1Hr1G087940/50 } & \multirow[t]{2}{*}{$1 \mathrm{H}$} & \multirow{2}{*}{$\begin{array}{l}540,693,806- \\
540,698,431:-1\end{array}$} & \multirow[t]{2}{*}{1470} & \multirow[t]{2}{*}{489} & A0A287GM87 \\
\hline & & & & & & A0A287GM65 \\
\hline HVWOX11 & HORVU2Hr1G017270 & $2 \mathrm{H}$ & $\begin{array}{l}40,107,707- \\
40,111,565: 1\end{array}$ & 927 & 308 & A0A287H773 \\
\hline HVWOX4 & HORVU2Hr1G113820 & $2 \mathrm{H}$ & $\begin{array}{l}729,806,496- \\
729,808,073: 1\end{array}$ & 1151 & 228 & A0A287JHP1 \\
\hline HvWOX10.1 & HORVU3Hr1G013290 & $3 \mathrm{H}$ & $\begin{array}{l}28,673,837- \\
28,674,948:-1\end{array}$ & 786 & 261 & M0Y8G7 \\
\hline HvWOX10.2 & HORVU3Hr1G013330 & $3 \mathrm{H}$ & $\begin{array}{l}28,785,048- \\
28,786,156:-1\end{array}$ & 815 & 261 & A0A287K575 \\
\hline HVWOX7 & HORVU3Hr1G060950 & $3 \mathrm{H}$ & $\begin{array}{l}464,417,446- \\
464,421,050: 1\end{array}$ & 2027 & 516 & A0A287L9L2 \\
\hline HvWOX8.1 & HORVU3Hr1G080660 & $3 \mathrm{H}$ & $\begin{array}{l}589,829,423- \\
589,834,968:-1\end{array}$ & 3229 & 267 & $\mathrm{M} 0 \times 0 \times 0$ \\
\hline HvWOX8.2 & HORVU3Hr1G080690 & $3 \mathrm{H}$ & $\begin{array}{l}590,115,430- \\
590,116,290: 1\end{array}$ & 584 & 130 & A0A287LWD8 \\
\hline HVWOX9 & HORVU3Hr1G085050 & $3 \mathrm{H}$ & $\begin{array}{l}\text { 610,834,437- } \\
610,835,788:-1\end{array}$ & 1165 & 209 & F2E473 \\
\hline HVWOX14 & HORVU3Hr1G086430 & $3 \mathrm{H}$ & $\begin{array}{l}616,993,938- \\
616,996,482:-1\end{array}$ & 1216 & 283 & M0XTJ6 \\
\hline HVWOX13 & HORVU3Hr1G086450 & $3 \mathrm{H}$ & $\begin{array}{l}617,085,484- \\
617,087,698: 1\end{array}$ & 824 & 274 & A0A287M365 \\
\hline HVWOX6 & HORVU4Hr1G051530 & $4 \mathrm{H}$ & $\begin{array}{l}423,508,136- \\
423,511,456:-1\end{array}$ & 1710 & 306 & MOY4Z0 \\
\hline HVWOX5 & HORVU5Hr1G022120 & $5 \mathrm{H}$ & $\begin{array}{l}111,001,136- \\
111,003,388: 1\end{array}$ & 1046 & 276 & A0A287QMF0 \\
\hline HvWOX3 & HORVU5Hr1G049190 & $5 \mathrm{H}$ & $\begin{array}{l}381,765,625- \\
381,766,908: 1\end{array}$ & 1126 & 186 & A0A287R4V3 \\
\hline HvWUS & & $2 \mathrm{H}$ & $\begin{array}{l}\text { 717,822,805- } \\
717,905,740:-1\end{array}$ & 942 & 313 & \\
\hline
\end{tabular}

Identification of WUS homologous genes in Triticeae plant species

In the six Triticeae plant species, only one transcript of WUS gene was annotated as TaWUSa on chromosome 2A in wheat in the database (Table 1). We found the homologous fragments of TaWUSa on chromosomes 2B and 2D in wheat (Table 1), 2D in A. tauschii (Table S1), 2A and 2B in T. dicoccoides and T. turgidum (Tables S2 and S3), and 2H in barley (Table 2). According to the results of multiple sequence alignment, the full length of the open reading frame (ORF) of these homologous genes can be achieved, and their deduced amino acid sequences were highly consistent 
with TaWUS (Fig. 1A). To understand if these genes can normally transcribe and express, promoter analysis was performed. It was showed that the promoter region of the WUS genes in the six Triticeae plant species all contained core promoter elements including transcription start TATA-box and AT TATA-box,indicating they possessed potential transcriptional activity (Fig. 1B). In the promoter region of TaWUSa, TdWUSa, TtWUSa, and TuWUS, a fragment of GGTCCAT was existed, which is a cis-acting regulatory element involved in auxin responsiveness. Nevertheless, this element was not detected in the promoter of AtaWUS, TaWUSb, TaWUSd, TdWUSb, and TtWUSb.

\section{Chromosomal location of WOX genes in Triticeae plant species}

In general, no WOX gene was found on homologous groups 6 and 7 for the genomes of the six Triticeae plant species, i.e., T. aestivum, T. turgidum, T. dicoccoides, H. vulgare, A. tauschii, and T. urartu, (Tables 1 and 2, and Tables S1-S4). In T. aestivum, except TaWUS, all the TaWOX genes had three copies of transcripts on its genomes A, B, and D. Three homologous alleles of TaWUS were located on chromosomes 2A, 2B, and 2D. The homologous genes of TaWOX2 or TaWOX12 were located on chromosomes 1A, 1B, and 1D. Three copies of TaWOX4 or TaWOX11 were located on chromosomes 2A, 2B, and 2D. The three homologous genes of TaWOX7to TaWOX10, TaWOX13 and TaWOX14 were all located on chromosomes 3A, 3B, and 3D. The three alleles of TaWOX6 were located on chromosomes 4A, 4B, and 4D. The three alleles of TaWOX3 or TaWOX5 were located on chromosomes 5A, 5B, and 5D. Further investigation would be needed for the unknown chromosomal location of an incomplete transcript of TaWOX8. No WOX gene was found on homologous groups 6 and 7 (Table 1, Fig. 2A). The HvWOX genes in H. vulgare showed the similar chromosomal localization to the TaWOX genes in T. aestivum and AtaWOX genes in A. tauschii. HvWOX2 and HvWOX12 were located on chromosome $1 \mathrm{H} ;$ HvWOX4 and HvWOX11 were located on chromosome 2H; HvWOX7 to HvWOX10, HvWOX13, and

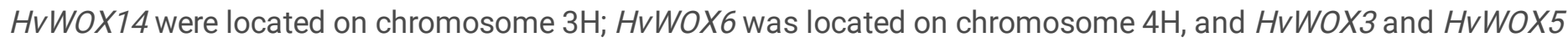
were located on chromosome $5 \mathrm{H}$. (Table 2; Fig. 2B). There are additional copies of HvWOX8 and HvWOX10 on chromosome $3 \mathrm{H}$. The HvWOX10.1 and HvWOX10.2 showed complete sequence consistency, but HvWOX8.2 was shortened compared with HVWOX8.1.

Similar situation was observed in A. tauschii. AtaWOX2 and AtaWOX12 were located on chromosome 1D. AtaWOX4 and AtaWOX11 were located on chromosome 2D. AtaWOX7 to AtaWOX10, AtaWOX13, and AtaWOX14 were all located on chromosome 3D. AtaWOX6 was located on chromosome 4D, AtaWOX3 and AtaWOX5 were located on chromosome 5D (Table S1, Fig. S1A). Similar results were also obtained in T. dicoccoides and T. turgidum. As expected, all the TdWOX and TtWOX genes were located on the corresponding chromosomes of their genomes $A$ and $B$ because the two species only have the two genomes (Table S2, Table S3, Fig. S1B, Fig. S1C). Additional copies of TdWOX8a and TtWOX14a were also existed on the corresponding chromosomes.

To verify the chromosomal locations of those WOX genes in the six Triticeae species, partial sequences of some of the WOX genes were amplified by their specific primers using a set of T. durum-T. aestivum genome D substitution lines (Fig. 3). The TaWUSa and its two homologs (named as TaWUSb and TaWUSd) were detected in T. aestivum L. cV CS (ABD genome), T. durum $c v$ Langdon (AB genome), and other substitution lines except 2D(2A), indicating that the two copies TaWUSa and TdWUSa were located on chromosome 2A. TaWUSb was amplified in CS, Langdon, and other substitution lines except 2D(2B), indicating that TaWUSb was located on chromosome 2B. TaWUSd only appeared in $\mathrm{CS}, 2 \mathrm{D}(2 \mathrm{~A})$ and 2D(2B), indicating that it was located on chromosome 2D (Fig. 3). Similarly, WOX2a, WOX2b, WOX6a, and WOX6b were absent in $1 \mathrm{D}(1 \mathrm{~A}), 1 \mathrm{D}(1 \mathrm{~B}), 6 \mathrm{D}(6 \mathrm{~A})$, and $6 \mathrm{D}(6 \mathrm{~B})$, respectively. WOX2d and WOX6d were only detected in $\mathrm{CS}$ and the substitution lines which contain chromosome 1D or 4D (Fig. 3).

\section{Evolution of WOX family proteins in Triticeae plant species}


Phylogenetic trees of WOX family proteins in Triticeae species were constructed based on the deduced protein sequences. From the phylogenetic trees, it was suggested that WOX proteins in Triticeae plants were also divided into three clades, like those in many other plant species [44, 45]. However, the WOX protein classification in wheat was closer to that in rice in comparison with that in Arabidopsis. TaWUS, TaWOX2 to TaWOX5, TaWOX9, TaWOX13, and TaWOX14 were assigned to the same clade with the homologous proteins in rice, corresponding to Arabidopsis WUS clade (AtWUS and AtWOX1 to AtWOX7). TaWOX6, TaWOX7, and TaWOX10 to TaWOX12, and their homologous proteins from rice were classified into a clade, corresponding to an Arabidopsis intermediate clade (AtWOX8, 9, 11, and 12). TaWOX8 and OsWOX8 were clustered in separated branches, showing correspondence to an Arabidopsis ancient clade (AtWOX10, 13, and 14) (Fig. 4).

Barley WOX proteins were also divided into three clades: the first clade harbored HvWOX2, 3, 5, 9, 13 and 14; the second clade was for HvWOX8 only; and the third clade included HvWOX6, 7, and 10 to 12 (Fig. S2A). Similar to wheat, one branch in A. tauschii contained AtaWOX2 to AtaWOX5, 9, 13 and 14. AtaWOX6, 7, and 10 to 12 were clustered into the same branch, but AtaWOX8 was belonged to another branch alone (Fig. S2B). In T. turgidum, TtWOX proteins were also divided into three clades: TtWOX2 to TtWOX5, 9, 13 and 14 were in the first branch; TtWOX6, 7, and 10 to 12 were in the second branch; and the three copies of TtWOX8 were clustered into the same group with OsWOX8 (Fig. S2C). In T. dicoccoides, TdWOX2 to TdWOX5, 9, 13 and 14 were clustered in one branch, TdWOX8 was in other branch alone, and TdWOX6, 7, and 10 to 12 were in another branch (Fig. S2D). In T. urartu, only eight sequences coding WOX family proteins were retrieved because there was no complete genome information on $T$. urartu yet. The deduced protein sequences from gene sequences of TuWOX and OsWOX were used to construct a phylogenetic tree, in which TuWOX2, 5, and 9 were grouped together, and TuWOX10 and TuWOX6/11 were in the same branch, and the two homologous sequences of TuWOX8 were clustered together (Fig. S2E).

The phylogenetic tree of the WOX family proteins from the six Triticeae species was also constructed via maximum likelihood method (Fig. 5). Based on the tree, it was clearly seen that the WOX proteins with the same names from the six Triticeae species were clustered together (Fig. 5), indicating that the WOX proteins were conserved in these plant species.

\section{Analysis for the conserved motifs of WOX proteins in Triticeae species}

All the amino acid sequences of WOX proteins in the six Triticeae species were deduced from their transcripts mentioned above. Each member contained HOX homeodomain, which were the most noteworthy symbol and defining feature of this protein family (Fig. 6, Fig. S3). Sequences of HOX homeodomain of the three clades of WOX proteins were conserved in the six Triticeae species (Fig. 7A). The conserved WUS-box motif TLXLFPXX (TL-[DEQP]-LFP-[GITVL][GSKNTCV]) was found in TaWUS, WOX2 to WOX5, and WOX9 in these Triticeae species (Fig. 6A, Fig. 7B). While, there was one amino acid residue change in ELXLFPXX of TaWUS and LLXLFPXX of WOX13 and WOX14 in the Triticeae species (Fig. 7B). The carboxy-terminal ERF-associated amphiphilic repression (EAR) domain of L-[ED]-L-[RST]-L only exists in WUS and WOX9 (Fig. 6A), and EAR domain of WOX9 in these Triticeae species showed highly conserved (Fig. 7C).

\section{Expression patterns of TaWOX genes in different organs of wheat}

The WOX genes mainly expressed in the meristematic region, and played a regulatory role in the process of plant growth and tissue differentiation. We retrieved the data from expVIP website (http://wheat-expression.com), and sketched the contours of expression pattern of TaWOX genes. It is showed that TaWUS expressed in root during seedling stage, in spike during vegetative stage, and in spike and leave/shoot during productive stage. Its expression level was higher in

spike than other organs (Fig. S4A). All the three homologous of TaWOX2 to 4, 7, 8, and 12 showed higher expression 
level in developing spike than other organs, and even higher at vegetative stage than reproductive stage (Fig. S4B-D, G, $\mathrm{H}$, and $\mathrm{L}$ ). The expression level of TaWOX5 was higher in grain than that in other organs at reproductive stage (Fig. S4E). TaWOX6, 9 to 11 showed a high transcriptional activity in root (Fig. S4F, I-K). The transcripts of TaWOX10 and TaWOX11 mainly accumulated in root at seedling stage while the expression level of TaWOX9 was high in root at vegetative stage (Fig. S4I-K). The transcript levels of TaWOX6b and TaWOX6d in root were increased at productive stage compared with vegetative stage (Fig. S4F).

Further, we used wheat root, stem, leave, spike at booting stage, and anther at heading stage as well as immature embryo, callus derived from the immature embryos at proliferative and differential stages as materials to perform expression profiling analysis of TaWOX genes by qPCR assay. The results indicated that expression patterns of TaWOX genes changed greatly in different organs at different stages (Fig. 8). The expression levels of TaWUS and TaWOX6 to 8 were relative high in spike (Fig. 8A, B), and the expression levels of TaWOX9 and TaWOX11 were high in root (Fig. 8B, C). Additionally, TaWOX2 showed high activity in embryo, and TaWOX3 and TaWOX4 showed high expression levels in embryogenic callus and differential callus, respectively (Fig. 8A).

\section{Discussion}

In Triticeae plant species, wheat and barley are two important crops globally, which account for a large proportion of food production in the world. With the completion of assemble and annotation of the colossal wheat genome, a great progress on functional genomic study in Triticeae plants, especially in wheat, has been achieved [46-49]. It is wellknown that wheat genome was originated from the natural hybridization of its three ancestor species. Therefore, wheat genome consisting of three genomes of $A, B$, and $D$ has a large number of repeated gene sequences, and most wheat genes have three or more copies [50]. In present study, we identified 43 WOX gene copies in the genome of T. aestivum, 42 of which was consistent with the result reported by Li et al. [51], and a new locus of TaWOX8 was added to the results of TaWOX family. Particularly, we firstly identified 17 WOX genes in $H$. vulgare, 13 in A. tauschii, 30 in $T$. turgidum, 25 in T. dicoccoides, and 8 in T. urartu. There were still several duplicated copies of WOX gene such as TaWOX14a, TaWOX14d, HvWOX10, and TdWOX14. A few of WOX-like pseudo genes were found to be scattered over Triticeae genomes, which might be a duplication of WOX genes or the other genes losing transcriptional activity during their evolution progress.

WUS plays an indispensable role on the stem cell niche maintenance in shoot apical meristem (SAM), lateral primordia differentiation and other diverse cellular processes [26]. The deficiency of WUS gene will lead to the loss of function of SAM and terminated plant growth [25]. However, only the allele of TaWUS located on chromosome 2A was annotated as a transcript. TdWOX12a, TdWOX12b, TdWOX7b and TdWOX13b, which have a high sequence identity with their homologous genes from wheat, were also not annotated as transcripts in the database. The DNA sequences and deduced protein sequences of four genes TdWOX12a, TdWOX12b, TdWOX7b, and TdWOX13b were added into the WOX members in the six Triticeae species (Table S2). In barley, the annotation of HORVU1Hr1G087940 and HORVU1Hr1G087950 and their deduced protein sequences A0A287GM87 and A0A287GM65 are actually originated from HvWOX12 (Table 2).

In previous studies, the classification and naming of WOX genes in wheat were confused to some extent. This might be attributed to the different naming scheme of WOX genes in Arabidopsis and rice [15, 23, 24]. For example, the TaWOX5 reported by Zhao et al. [52] were regarded as TaWOX9 due to their highly similarity to OsWOX9, even though it showed a close similarity to AtWOX5 in all the WOX members in Arabidopsis (Fig. 4). Several reported TaWOX members such as TraesCS3A02G358100, TraesCS3B02G391100, TraesCS3D02G352500, TraesCS3A02G358200, TraesCS3A02G358400, TraesCS3B02G391200, TraesCS3D02G352600, and TraesCS3D02G352700 on chromosomes 3A, 3B, and 3D, respectively, were named as TaWOX13 and TaWOX14[51] according to new nomination regulation. However, TaWOX13 
was not similar to AtWOX13 or OsWOX13, and AtWOX14 was also not similar to AtWOX14 in transcripts. While, TaWOX13 and TaWOX14 were similar to the homologs of TaWOX5 according to phylogenic analysis (Fig. 4). The WOX13 and WOX14 in other Triticeae species showed the similar phylogenetic relationship with WOX5 members (Fig. 5).

All the TaWOX genes in wheat have three or more copies. Due to their sequence similarity, it is difficult to distinguish the expression level of each copy of TaWOX genes. A feasible approach was applied to estimate the amount of mRNA by calculating transcript amount of each copy. Zhao et al. indicated that the transcriptional level of individual TaWOX5 allele was varied during the period of callus growth in wheat [52]. Based on the results in the present investigation, the expression profiles of other WOX alleles were also changed in different wheat organs, which need to be justified by further research.

\section{Conclusions}

To our knowledge, this is the first study on genome-wide and contrastive analysis on WOX family genes in Triticeae plant species. In total, 130 WOX genes were identified, including 43 in T. aestivum, 28 in T. turgidum, 23 in T. dicoccoides, 15 in H. vulgare, 13 in A. tauschii, and 8 in T. urartu. The homologous genes of TaWUSb, TaWUSd, and WUS in other five Triticeae species were annotated, which were predicted to express normally according to promoter element analysis. Four novel homologous alleles of TaWOX genes including TdWOX12a, TdWOX12b, TdWOX7b, and TdWOX13b were also identified in T. dicoccoides. All of these WOX members showed evolutionary conservation and same chromosomal location arrangement. Based on the RNA-seq data in wheat-expression database and qPCR array results, TaWOX genes were found to have tissue-specific expression feature. The results showed in this study would be helpful to further understand the molecular function and evolutionary relationship of WOX family genes in Triticeae plants, and potentially apply them in plant genetic transformation in the future.

\section{Methods}

\section{Materials and cultivation conditions}

Wheat line Chinese Spring (CS) stored in our laboratory was used as the plant material to conduct gene identification and expression analyses. A set of T. durum-T. aestivum genome D substitution lines and their genetic background Langdon (LD), which were kindly provided by Dr. Steven Xu at the Northern Plains Crop Science Laboratory of the USDAARS, North Dakota, USA, and genetically identified by Prof. Zhishan Lin at the institute of Crop Sciences (ICS), Chinese Academy of Agricultural Sciences (CAAS), Beijing, China, were used to verify the chromosomal localization of the WOX genes identified in this study. In each of these disomic substitution lines, a pair of A-genome or B-genome chromosome in the tetraploid wheat T. durum was replaced by a corresponding pair of D-genome chromosomes from T. aestivum. For example, in substitution line 1D(1A) chromosome 1D from $T$. aestivum $\mathrm{D}$ replaces the chromosome $1 \mathrm{~A}$ in $T$. durum. Thirty seeds of those wheat materials were planted as a trail with $1 \mathrm{~m}$ in length and $20 \mathrm{~cm}$ in width in the experimental station of ICS, CAAS, Beijing, China, under natural soil conditions without stress.

\section{Rna Isolation And Qpcr Analysis}

The wheat samples for roots, stems, and leaves were collected at three-leaf stage, for young spikes at booting stage, and for anthers at heading stage. The immature embryo samples were collected 15 days post anthesis (DPA). Callus samples were induced from the immature embryos on MS medium containing 2,4-D $2.0 \mathrm{mg} \mathrm{L}^{-1}$ under dark condition 
and collected after cultured for one week and two weeks, respectively. The calli were cultured for differentiation on $1 / 2$ MS medium containing $5.0 \mathrm{mg} \mathrm{L}^{-1}$ Zeatin in a photoperiod of $14 \mathrm{~h}$-light and $10 \mathrm{~h}$-darkness and sampled one week later.

Total RNA was extracted using TRIzol ${ }^{\mathrm{TM}}$ Reagent Kit (Invitrogen 15596026), and reverse transcription reaction was performed using the PrimeScript ${ }^{\mathrm{TM}} \mathrm{RT}$ reagent (Takara) according to the manufacturer's protocol. The qPCR was performed on ABI7500 Thermal Cycler using $2 \times$ RealStar Green Fast Mixture (with ROX II, Genestar). TaActin (Genbank: $A B 181991)$ was used as internal controls, and three biological replicates were adopted. Gene-specific primers were designed with premiere primer 6.0 (Table S5). Each qPCR reaction system $(20 \mu \mathrm{L})$ contained $10 \mu \mathrm{L}$ of $2 \times$ RealStar Green Fast Mixture, $0.4 \mu \mathrm{L}$ of forward primer $(10 \mathrm{mM}), 0.4 \mu \mathrm{L}$ of reverse primer $(10 \mathrm{mM})$ and $1 \mu \mathrm{L}$ of diluted cDNA $\left(200 \mathrm{ng}^{2} \mathrm{~L}^{-}\right.$

$\left.{ }^{1}\right)$. The thermal cycling conditions were $95^{\circ} \mathrm{C}$ for $5 \mathrm{~min}, 40$ cycles of amplification $\left(95^{\circ} \mathrm{C}\right.$ for $15 \mathrm{~s}, 60{ }^{\circ} \mathrm{C}$ for $15 \mathrm{~s}$, and $72{ }^{\circ} \mathrm{C}$ for $30 \mathrm{~s}$ ), and $95^{\circ} \mathrm{C}$ for $10 \mathrm{~s}$ at dissociation stage, followed by $65-95^{\circ} \mathrm{C}$ with increments of $0.5^{\circ} \mathrm{C}$ for $0.05 \mathrm{~s}$.

\section{Database used for searching WOX family genes in Triticeae plants}

Twenty-six predicted WOX family protein sequences of wheat were obtained from Plant TFDB database (http://planttfdb.cbi.pku.edu.cn), and retrieved Genbank (https://www.ncbi.nlm.nih.gov/genbank) with AtWOX of Arabidopsis, OsWOX of rice, and ZmWOX of maize (Zea mays). Using all of the protein sequences above as queries to conduct TBLASTN search on Gramene (http://ensembl.gramene.org/Tools/Blast) and URGI (https://urgi.versailles.inra.fr) for the identification of WOX proteins encoded genes in wheat genomes. Then, BLASTN search with sequences of TaWOX genes was performed in the genomes of H. vulgare, T. urartu, T. dicoccoides, T. turgidum, and $A$. tauschii. All the genetic analysis was carried out using these protein sequences of the six Triticeae plants. Based on the BLAST results from Gramene and URGI, the WOX genes from the Triticeae plants were located on exact chromosomes. The location chart was made by MapGene2Chrom web v2.1 (http://mg2c.iask.in/mg2c_v2.1/).

\section{Dna Isolation And Pcr Analysis}

Wheat genomic DNA was isolated by NuClean Plant Genomic DNA kit (Cwbio, CW0531M) from the leaf samples at three-leaf stage. PCR reaction system $(20 \mu \mathrm{L})$ contained $10 \mu \mathrm{L}$ of $2 \times$ Taq Master Mix (containing $\mathrm{Mg}^{2+}$ and dNTP, Vazyme, China), $0.5 \mu \mathrm{L}$ of each forward primer and reverse primer $(10 \mathrm{mM})$, and $1 \mu \mathrm{L}$ of gDNA $\left(1 \mu \mathrm{g} \mu \mathrm{L}^{-1}\right)$, adding $\mathrm{ddH}_{2} \mathrm{O}$ up to $20^{\circ} \mathrm{C}$. Sequences of all the primers used for the detection were shown in Table S6. The thermal cycling conditions were $94{ }^{\circ} \mathrm{C}$ for $5 \mathrm{~min}, 35$ cycles of $94^{\circ} \mathrm{C}$ for $20 \mathrm{~s}, 60^{\circ} \mathrm{C}$ for $20 \mathrm{~s}, 72{ }^{\circ} \mathrm{C}$ for $30 \mathrm{~s}$, and then $72{ }^{\circ} \mathrm{C}$ for $10 \mathrm{~min}$.

\section{Phylogenetic Trees Construction}

The full-length of the WOX proteins of Triticeae species were aligned by ClustalW algorithm. Phylogenetic analysis and phylogenetic tree construction were performed by the MEGA X program (https://www.megasoftware.net/) using maximum approach and 1000 bootstrap replicates. Sequences of TaWOX proteins were aligned with AtWOX and OsWOX proteins, and phylogenetic tree was constructed to confirm classification and phylogenetic relationship of the identified TaWOX members. Then taking OsWOX proteins as model, the phylogenetic trees were constructed between OsWOX and HvWOX, OsWOX and TdWOX, OsWOX and TtWOX, OsWOX and AtaWOX members to name and classify the WOX members in the six Triticeae species.

\section{Conserved Protein Motif Analysis}


The conserved domain HD, was identified by SMART software (http://smart.embl-heidelberg.de/). The distinctive WUSbox motif as TLXLFPXX(T-L-[DEQP]-L-F-P-[GITVL]-[GSKNTCV]) and the EAR domain as LXLXL(L-[ED]-L-[RST]-L) were both defined in a strict sense. TEXshade software was employed to perform the multiple sequence alignments for HD domains, WUS-box motifs, and EAR motifs. The logo diagrams were drawn by canonical conserved residues including HD domains, WUS-box motifs, and EAR motifs by SeqLOGO in TBTools.

\section{Expression analysis of TaWOX genes using RNA-seq data}

RNA-seq data of 43 TaWOX genes was downloaded from expVIP (http://wheat-expression.com/). The expression level in root and leaves/shoot at seedling stage, in root and leaves/shoot spike at vegetative stage, and in root, spike, grain at vegetative stage were analyzed and compared.

\section{Statistical analysis}

The SPSS 19.0 software package was employed to statistically analyze the expression data of the target genes achieved by qPCR. Statistical comparisons of multiple sets of data was carried out by Duncan's multiple range test. The histogram was made using the Excel software.

\section{Abbreviations}

ARF: Auxin response factor; BBM: BABY BOOM; CLE41: CLAVATA3/ESRLIKE41; CLV3: CLAVATA3; CS: Chinese Spring; CSC: columella stem cell; CUC: CUP-SHAPED COTYLEDON; DPA: days post anthesis; EAR: ERF-associated amphiphilic repression; HB: homeobox; HD: homeodomain; LEC2: LEAFY COTYLEDON2; OC: organizing-center; ORF: open reading frame; PFS2: PRETTY FEW SEEDS2; PIN1: PINFORMED1; PLT: PLETHORA; PRS1: PRESSED FLOWER1; PXY: PHLOEM INTERCALATED WITH XYLEM; qPCR: quantitative real-time PCR; RNA-seq: RNA sequencing; SAM: shoot apical meristem; SCR: SCARECROW; SHR: SHORT ROOT; WOX: WUSCHEL-related homeobox; YUC:YUCCA.

\section{Declarations}

\section{Acknowledgments}

We thank Dr. Steven Xu at the Northern Plains Crop Science Laboratory of the USDAARS, North Dakota, USA, for providing a set of T. durum-T. aestivum genome D substitution lines.

\section{Funding}

This research was financially supported by the National Natural Science Foundation of China (31971946), and the Chinese Academy of Agricultural Sciences in China (2060302-2-19). The funders had no role in the designing and conducting of this study and collection, analysis, and interpretation of data and in writing the manuscript.

\section{Availability of data and material}

All data used or analyzed in this study are included in this published article and additional files. Twenty-six predicted WOX family protein sequences of wheat could be downloaded from Plant TFDB database (http://planttfdb.cbi.pku.edu.cn). Genome sequences and annotation of WOX genes in the six Triticeae species could be downloaded from Gramene (http://ensembl.gramene.org/Tools/Blast) and URGI (https://urgi.versailles.inra.fr). Transcriptome data used for gene expression analysis could be downloaded from expVIP (http://wheatexpression.com/). 


\section{Authors' contributions}

The experiment was conceived by XY and HL. LS and HL analyzed the data, KW and XS assisted with bioinformatics analysis. LS performed the PCR and qPCR experiments. The manuscript was drafted by LS, XY and HL, and corrected and approved by all authors.

\section{Ethics approval and consent to participate}

Not applicable.

\section{Consent for publication}

Not applicable.

\section{Competing interests}

The authors declare that they have no competing interests.

\section{References}

1. FAOSTAT (2020) http://www.fao.org/faostat/en/, Accessed date: 10 Augest 2020.

2. Feuillet C, Muehlbauer GJ. Genetics and Genomics of the Triticeae. Springer, 2009.

3. IWGSC, et al. Shifting the limits in wheat research and breeding using a fully annotated reference genome. Science. $2018 ; 361$.

4. Singh RK, Prasad M. Advances in Agrobacterium tumefaciens-mediated genetic transformation of graminaceous crops. Protoplasma. 2016; 253: 691-707.

5. Wang K, Gong Q, Ye X. Recent developments and applications of genetic transformation and genome editing technologies in wheat. Theor Appl Genet. 2020; 133: 1603-1622.

6. Ye X, Shirley S, Xu H, Du L, Clement T. Regular production of transgenic wheat mediated by Agrobacterium tumefaciens. Agri Sci China. 2002; 1: 239-244.

7. Wang K, Liu H, Du L, Ye X. Generation of marker-free transgenic hexaploid wheat via an Agrobacterium-mediated cotransformation strategy in commercial Chinese wheat varieties. Plant Biotechnol J. 2017; 15: 614-623.

8. Kareem A, Durgaprasad K, Sugimoto K, Du Y, Pulianmackal AJ, Trivedi ZB, et al. PLETHORA Genes Control Regeneration by a Two-Step Mechanism. Curr Biol. 2015; 25: 1017-1030.

9. Kumar V, Jha P, Van Staden J. LEAFY COTYLEDONs (LECs): master regulators in plant embryo development. Plant Cell Tiss Org. 2020; 140: 475-487.

10. Pan J, Zhao F, Zhang G, Pan Y, Sun L, Bao N, et al. Control of de novo root regeneration efficiency by developmental status of Arabidopsis leaf explants. J Genet Genomics. 2019; 46: 133-140.

11. Xu J, Hofhuis H, Heidstra R,1 Sauer M, Friml J, Scheres B. A molecular framework for plant regeneration. Science.2006; 311: 386-388.

12. Xu L. De novo root regeneration from leaf explants: wounding, auxin, and cell fate transition. Curr Opin Plant Biol. 2018; 41: 39-45.

13. Lowe K, Wu E, Wang N, Hoerster G, Hastings C, Cho MJ, et al. Morphogenic regulators Baby boom and Wuschel improve monocot transformation. Plant Cell. 2016; 28: 1998-2015.

14. Lowe K, La Rota M , Hoerster G ,Hastings C, Wang N, Chamberlin M, et al. Rapid genotype "independent" Zea mays L. (maize) transformation via direct somatic embryogenesis. In Vitro Cell Dev-PI. 2018; 54: 240-252. 
15. Van der Graaff E, Laux T, Rensing SA. The WUS homeobox-containing (WOX) protein family. Genome Biology 2009; 10: 248.

16. Gehring WJ, Muller M, Affolter M, Percival-Smith A, Billeter M, Qian YQ, et al. The structure of the homeodomain and its functional implications. Trends Genet, 1990; 6: 323-329.

17. Gehring WJ, Qian YQ, Billeter M, Furukubo-Tokunaga K, Schier AF, Resendez-Perez D, et al. Homeodomain-DNA recognition. Cell. 1994; 78: 211-223.

18. Breuninger H, Rikirsch E, Hermann M, Ueda M, Laux T. Differential expression of WOX genes mediates apical-basal axis formation in the Arabidopsis embryo. Dev. Cell. 2008; 14: 867-876.

19. Hao Q, Zhang L, Yang Y, Shan Z, Zhou XA. Genome-wide analysis of the WOX gene gamily and gunction exploration of GmWOX18 in soybean. Plants. 2019; 8: 215.

20. Costanzo E, Trehin C, Vandenbussche M. The role of WOX genes in flower development. Ann Bot. 2014;114: 15451553.

21. Dolzblasz A, Nardmann J, Clerici E, Causier B, van der Graaff E, Chen J, et al. Stem cell regulation by Arabidopsis WOX genes. Mol Plant. 2016; 9: 1028-1039.

22. Honda $\mathrm{E}$, Yew CL, Yoshikawa T, Sato Y, Hibara K, Itoh JI. LEAF LATERAL SYMMETRY1, a member of the WUSCHELRELATED HOMEOBOX3 gene family, regulates lateral organ development differentially from other paralogs, NARROW LEAF2 and NARROW LEAF3 in rice. Plant Cell Physiol. 2018; 59: 376-391.

23. Haecker A, Gross-Hardt R, Geiges B, Sarkar A, Breuninger H, Herrmann M, et al. Expression dynamics of WOX genes mark cell fate decisions during early embryonic patterning in Arabidopsis thaliana. Development. 2004; 131: 657568.

24. Zhang X, Zong J, Liu J, Yin J, Zhang D. Genome-wide analysis of WOX gene family in rice, sorghum, maize, Arabidopsis and poplar. J. Integr. Plant Biol. 2010; 52(11): 1016-1026.

25. Ma Y, Miotk A, Šutiković Z, Ermakova O, Wenzl C, Medzihradszky A, et al. WUSCHEL acts as an auxin response rheostat to maintain apical stem cells in Arabidopsis. Nat Commun, 2019; 10: 5093

26. Jha P, Ochatt SJ, Kumar V. WUSCHEL: a master regulator in plant growth signaling. Plant Cell Reports. 2020; 39 : 431-444.

27. Zuo J, Niu QW, Frugis G, Chua NH. The WUSCHEL gene promotes vegetative-to-embryonic transition in Arabidopsis. Plant J. 2002, 30: 349-359.

28. Gallois JL, Nora FR, Mizukami Y, Sablowski R. WUSCHEL induces shoot stem cell activity and developmental plasticity in the root meristem. Gene dev. 2004; 18(4): 375-380.

29. Zhang Y, Wu R, Qin G, Chen Z, Gu H, Qu L. Over-expression of WOX1 leads to defects in meristem development and polyamine homeostasis in Arabidopsis. J Integr Plant Biol. 2011; 53: 493-506.

30. Shimizu R, Ji J, Kelsey E, Ohtsu K, Schnable PS, Scanlon MJ. Tissue specificity and evolution of meristematic WOX3 function. Plant Physiol. 2009; 149: 841-50.

31. Wang F, Shang G, Wu L, Xu Z, ZhaoX, Wang J. Chromatin accessibility dynamics and a hierarchical transcriptional regulatory network structure for plant somatic embryogenesis. Dev Cell. 2020; 54: 1-16.

32. Suer S, Agusti J, Sanchez P, Schwarz M, Greb T. WOX4 imparts auxin responsiveness to cambium cells in Arabidopsis. Plant Cell. 2011; 23: 3247-3259.

33. Kong X, Lu S, Tian H, Ding Z. WOX5 is shining in the root stem cell niche. Trends Plant Sci. 2015; 20(10): 601-603.

34. Park SO, Zheng Z, Oppenheimer DG, Hauser BA. The PRETTY FEW SEEDS2 gene encodes an Arabidopsis homeodomain protein that regulates ovule development. Development. 2005; 132: 841-849. 
35. Kong D, Hao Y, Cui H. The WUSCHEL related Homeobox protein WOX7 regulates the sugar response of lateral root development in Arabidopsis thaliana. Mol Plant. 2016; 9: 261-270.

36. Wu X, Dabi T, and Weigel D. Requirement of homeobox gene STIMPY/WOX9 for arabidopsis meristem growth and maintenance. Curr Biol. 2005; 15: 436-440.

37. Wu X, Chory J, and Weigel D. Combinations of WOX activities regulate tissue proliferation during Arabidopsis embryonic development. Dev Biol. 2007; 309: 306-316.

38. Ueda M, Zhang Z, Laux T. Transcriptional activation of Arabidopsis axis patterning genes WOX8/9 links zygote polarity to embryo development. Dev Cell. 2011; 20: 264-270.

39. Baesso B, Chiatante D, Terzaghi M, Zenga D, Nieminen K, Mahonen AP, et al. Transcription factors PRE3 and WOX11 are involved in the formation of new lateral roots from secondary growth taproot in A. thaliana. Plant Biol. 2018; 20: 426-432.

40. Liu J, Sheng L, Xu Y, Li J, Yang Z, Huang H, et al. WOX11 and 12 are involved in the first-step cell fate transition during de novo root organogenesis in Arabidopsis. Plant Cell. 2014; 26: 1081-1093.

41. Romera-Branchat M, Ripoll JJ, Yanofsky MF, Pelaz S. The WOX13 homeobox gene promotes replum formation in the Arabidopsis thaliana fruit. Plant J. 2013; 73: 37-49.

42. Denis E, Kbiri N, Mary V, Claisse G, Conde ESN, Kreis M, et al. WOX14 promotes bioactive gibberellin synthesis and vascular cell differentiation in Arabidopsis. Plant J. 2017; 90: 560-572.

43. Etchells JP, Provost, CM, Mishra L, Turner SR. WOX4 and WOX14 act downstream of the PXY receptor kinase to regulate plant vascular proliferation independently of any role in vascular organisation. Development. 2013; 140: 2224-2234.

44. Lian G, Ding Z, Wang Q, Zhang D, Xu J. Origins and evolution of WUSCHEL-related homeobox protein family in plant kingdom. Sci World J. 2014; 534140

45. Wu CC, Li FW, Kramer EM. Large-scale phylogenomic analysis suggests three ancient superclades of the WUSCHELrelated homeobox transcription factor family in plants. PLoS ONE. 2019; 14(10): e0223521.

46. Hong, Seo. Genome-wide transcript analysis of inflorescence development in wheat. Genome, 2019; 62(9): 623633.

47. Jighly A, Joukhadar R, Sehgal D, Singh S, Ogbonnaya FC, Daetwyler HD. Population-dependent reproducible deviation from natural bread wheat genome in synthetic hexaploid wheat. Plant J. 2019; 100: 801-812.

48. Jiang W, Yin J, Zhang H, He Y, Shuai S, Chen S, et al. Genome-wide identification, characterization analysis and expression profiling of auxin-responsive GH3 family genes in wheat (Triticum aestivum L.). Mol Biol Rep. 2020; 47: 3885-3907.

49. Zhao Y, Li J, Zhao R, Xu K, Xiao Y, Zhang S, et al. Genome-wide association study reveals the genetic basis of cold tolerance in wheat. Mol Breeding, 2020; 40: 36.

50. Brenchley R, Brenchley R, Spannagl M, Pfeifer M, Barker GLA, D'Amore R, et al. Analysis of the bread wheat genome using whole-genome shotgun sequencing. Nature. 2012; 491: 705-710.

51. Li Z, Liu D, Xia Y, Li Z, Jing D, Du J, et al. Identification of the WUSCHEL-Related Homeobox (WOX) gene family, and interaction and functional analysis of TaWOX9 and TaWUS in wheat. Int. J. Mol. Sci. 2020; 21: 1581.

52. Zhao S, Jiang Q, Ma J, Zhang X, Zhao Q, Wang X, et al. Characterization and expression analysis of WOX5 genes from wheat and its relatives. Gene. 2014; 537: 63-69.

\section{Figures}


A

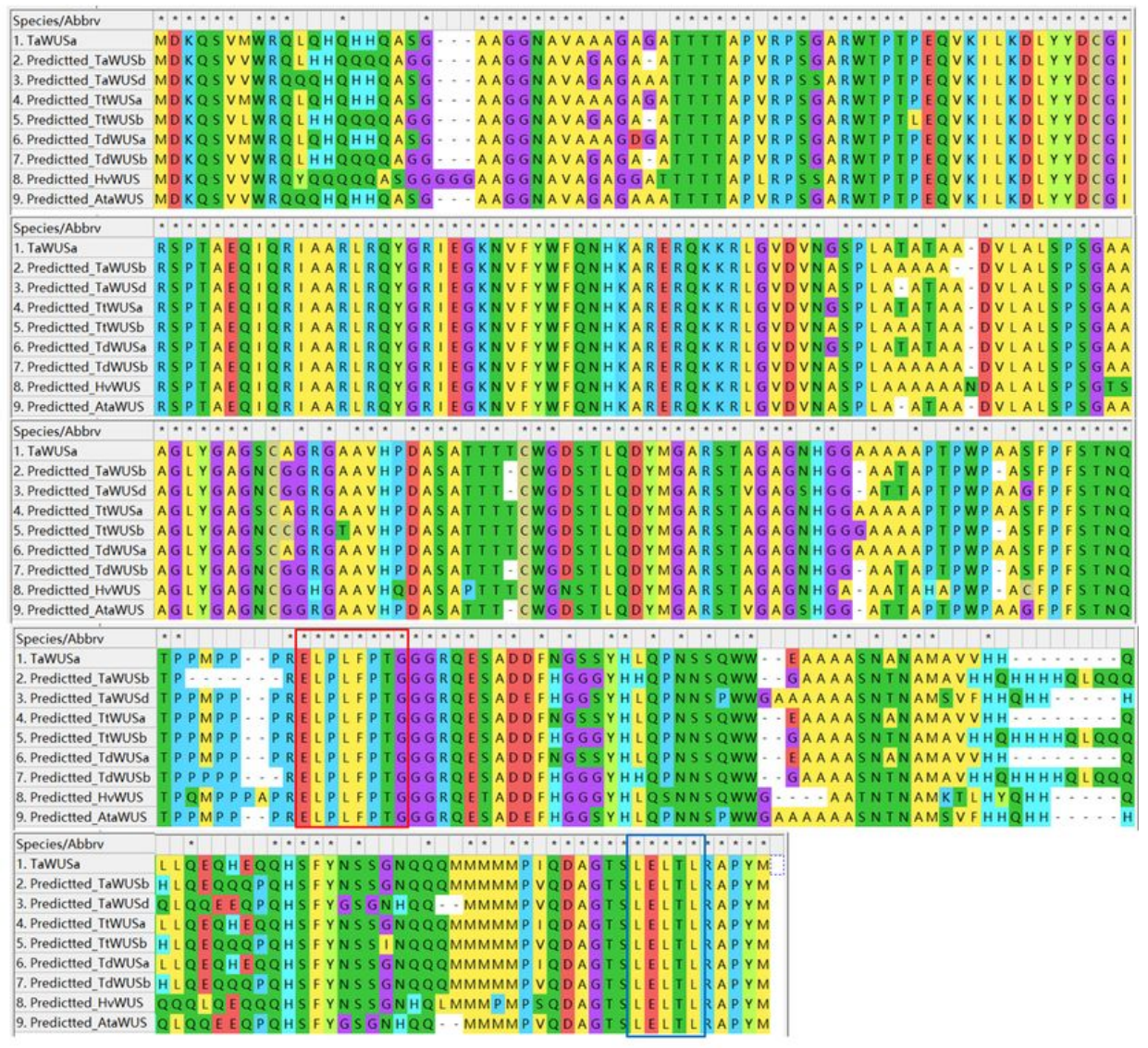

\section{B}

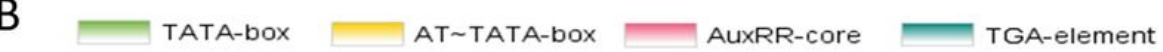

\section{Figure 1}

Multiple sequence alignment and element prediction of the promoters among TaWUS and other predicted WUS genes from the six Triticeae species. A. Multiple sequence alignment among TaWUS and other predicted WUS proteins. Alignment of protein sequences was conducted by ClustalW algorithm using MEGA X. The position of conserved WUSbox motif was shown in red box, and the position of EAR domain was shown in blue box. B. Element prediction of the promoter regions of TaWUS and other predicted WUS genes in the six Triticeae species. TATA-BOX elements and their positions in the promoters were displayed in green oval, AT TATA-BOX elements and their positions in yellow oval, cisacting regulatory elements involved in auxin responsiveness AuxRR-core and their positions in red oval, and auxinresponsive TGA-elements and their positions in blue oval. 
A
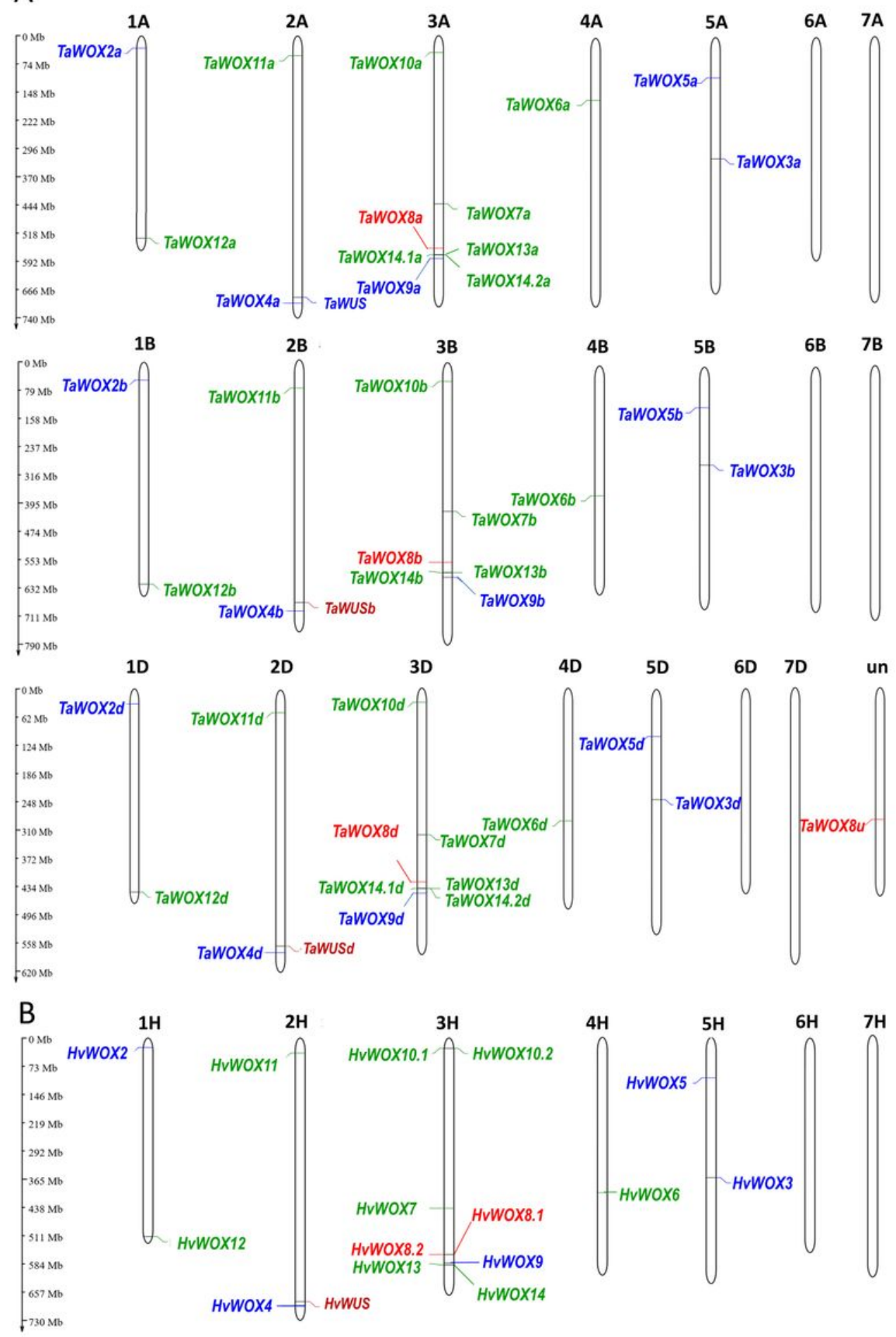

Figure 2

Chromosomal locations of WOX genes in T. aestivum (A) and H. vulgare (B). The number of chromosomes was labeled on the top of each chromosome. The location of each WOX genes was marked on the chromosome. The WOX members in WUS, intermediate and ancient clades were shown as blue, green and red types, respectively. The newly collected WOX members were shown as brown type. 


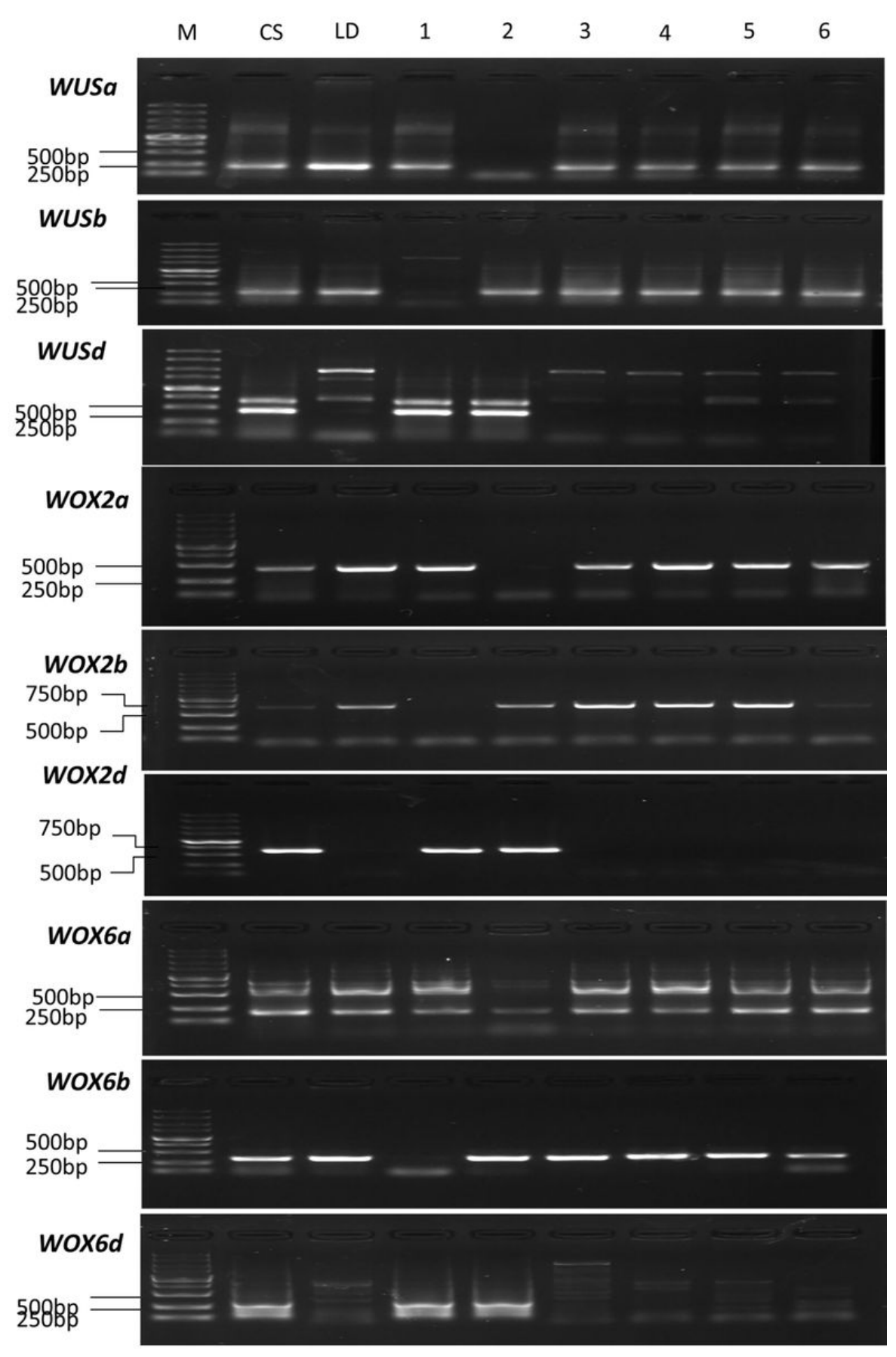

\section{Figure 3}

Verification of chromosomal locations of several TaWOX alleles by specific PCR amplification. Gel electrophoresis of specific fragments of TaWUS, TaWOX2 and TaWOX6 alleles. M, DNA molecular marker; CS, PCR product of Chinese Spring (T. aestivum); LD, PCR product of Langdon (T. durum); samples 1-6 in row WUSa were: substitution lines 2D(2B), $2 D(2 A), 1 D(1 A), 3 D(3 A), 4 D(4 A)$, and 5D(5A); samples 1-6 in row WUSb were: 2D(2B), 2D(2A), 1D(1B), 3D(3B), 4D(4B), and $5 D(5 B)$; samples 1-6 in row WUSd were: 2D(2B), 2D(2A), $1 D(1 A)$ and $1 D(1 B), 3 D(3 A)$ and $3 D(3 B), 4 D(4 A)$ and $4 D(4 B)$, and $5 D(5 A)$ and $5 D(5 B)$; samples 1-6 in row WOX2a were substitution lines 1D $(1 B), 1 D(1 A), 2 D(2 A), 3 D(3 A)$, $4 D(4 A)$, and $5 D(5 A)$; samples 1-6 in row WOX2b were $1 D(1 B), 1 D(1 A), 2 D(2 B), 3 D(3 B), 4 D(4 B)$, and $5 D(5 B)$; samples 1-6 in row WOX2d were $1 \mathrm{D}(1 \mathrm{~B}), 1 \mathrm{D}(1 \mathrm{~A}), 2 \mathrm{D}(2 \mathrm{~A})$ and $2 \mathrm{D}(2 \mathrm{~B}), 3 \mathrm{D}(3 \mathrm{~A})$ and $3 \mathrm{D}(3 \mathrm{~B}), 4 \mathrm{D}(4 \mathrm{~A})$ and $4 \mathrm{D}(4 \mathrm{~B})$, and $5 \mathrm{D}(5 \mathrm{~A})$ and $5 D(5 B)$; samples 1-6 in row WOX6a were substitution lines 4D(4B), 4D(4A), 1D(1A), 2D(2A), 3D(3A), and 5D(5A); 
samples 1-6 in row WOX6b were 4D(4B), 4D(4A), 1D(1B), 2D(2B), 3D(3B), and 5D(5B); samples 1-6 in row WOX6d were: $4 \mathrm{D}(4 \mathrm{~B}), 4 \mathrm{D}(4 \mathrm{~A}), 1 \mathrm{D}(1 \mathrm{~A})$ and $1 \mathrm{D}(1 \mathrm{~B}), 2 \mathrm{D}(2 \mathrm{~A})$ and $2 \mathrm{D}(2 \mathrm{~B}), 3 \mathrm{D}(3 \mathrm{~A})$ and $3 \mathrm{D}(3 \mathrm{~B})$, and $5 \mathrm{D}(5 \mathrm{~A})$ and $5 \mathrm{D}(5 \mathrm{~B})$.

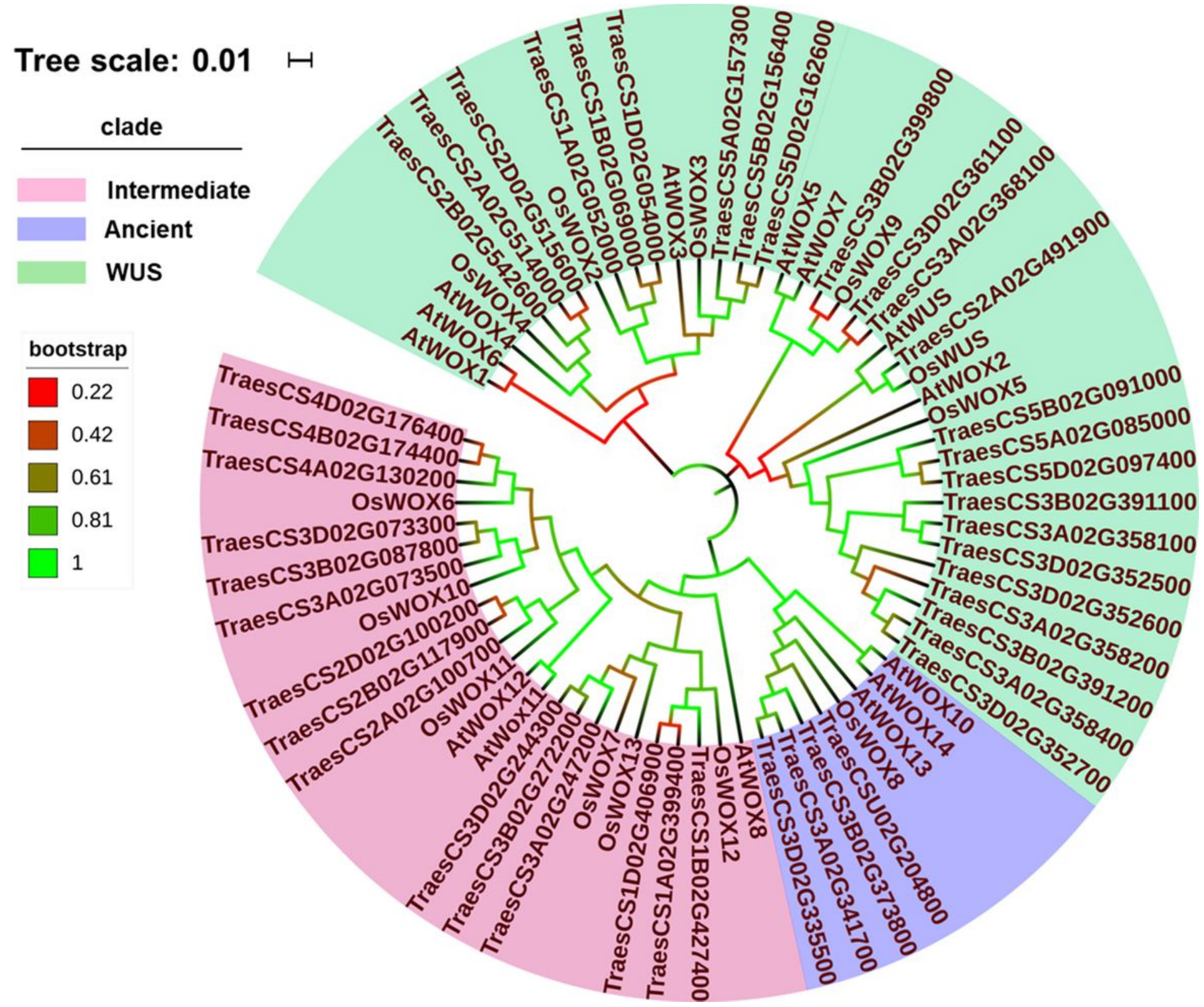

Figure 4

Phylogenetic relationships among WOX proteins in wheat, rice and Arabidopsis. Phylogenetic tree was constructed based on the sequences of WOX proteins in wheat, rice and Arabidopsis, performed by the MEGA X using neighborjoining approach with 1000 bootstrap replicates. WUS clade harbors WUS, WOX2 to WOX5, WOX9 in wheat and rice, TaWOX13, TaWOX14, AtWUS and AtWOX1 to AtWOX7; intermediate clade contains WOX6, WOX7, and WOX10 to WOX12 in wheat and rice, AtWOX8, 9, 11, and 12; and ancient clade contains WOX8 in wheat and rice, AtWOX10, 13, and 14. Scale plate and legend in upper left displayed tree scale and bootstrap value. 




Figure 5

Phylogenetic relationships among WOX proteins from wheat, barley, T. dicoccoides, T. turgidum, A. tauschii, and T. urartu. Phylogenetic tree was constructed based on the sequences of WOX proteins in six Triticeae species implemented by the MEGA X software using maximum likelihood method. Legend in upper left displayed colored ranges of WOX members. 
Tree scale: 0.01

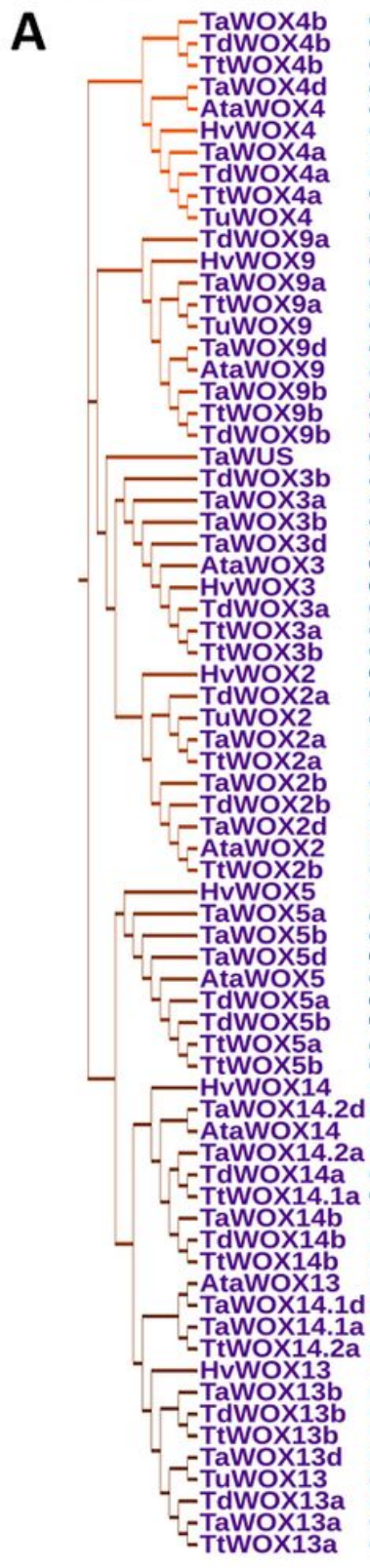

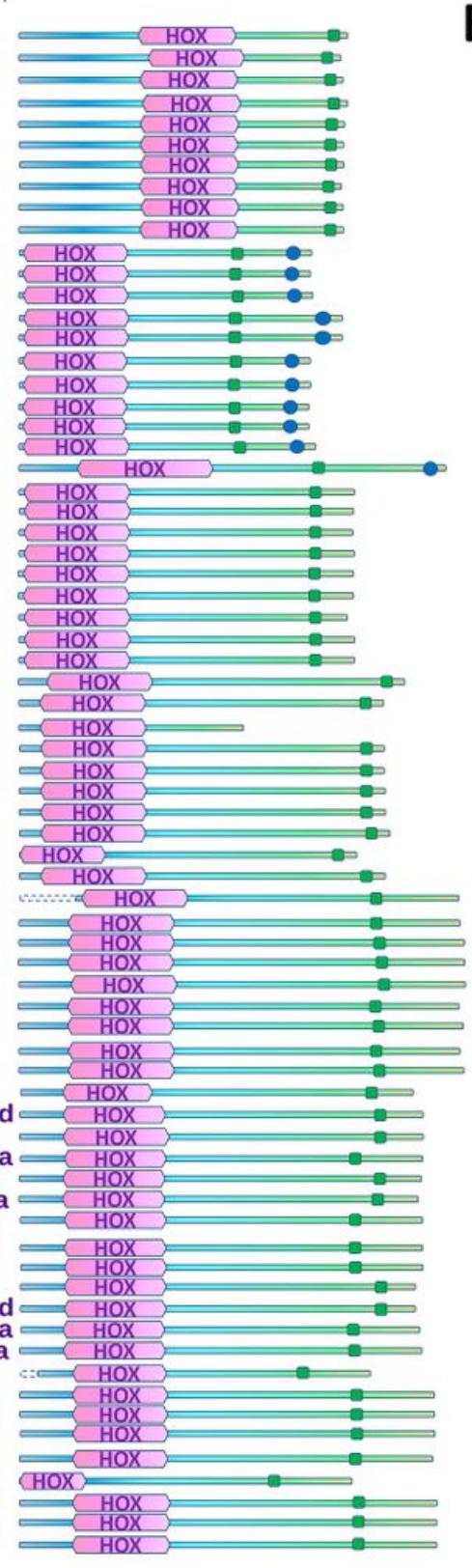

Tree scale: 0.01
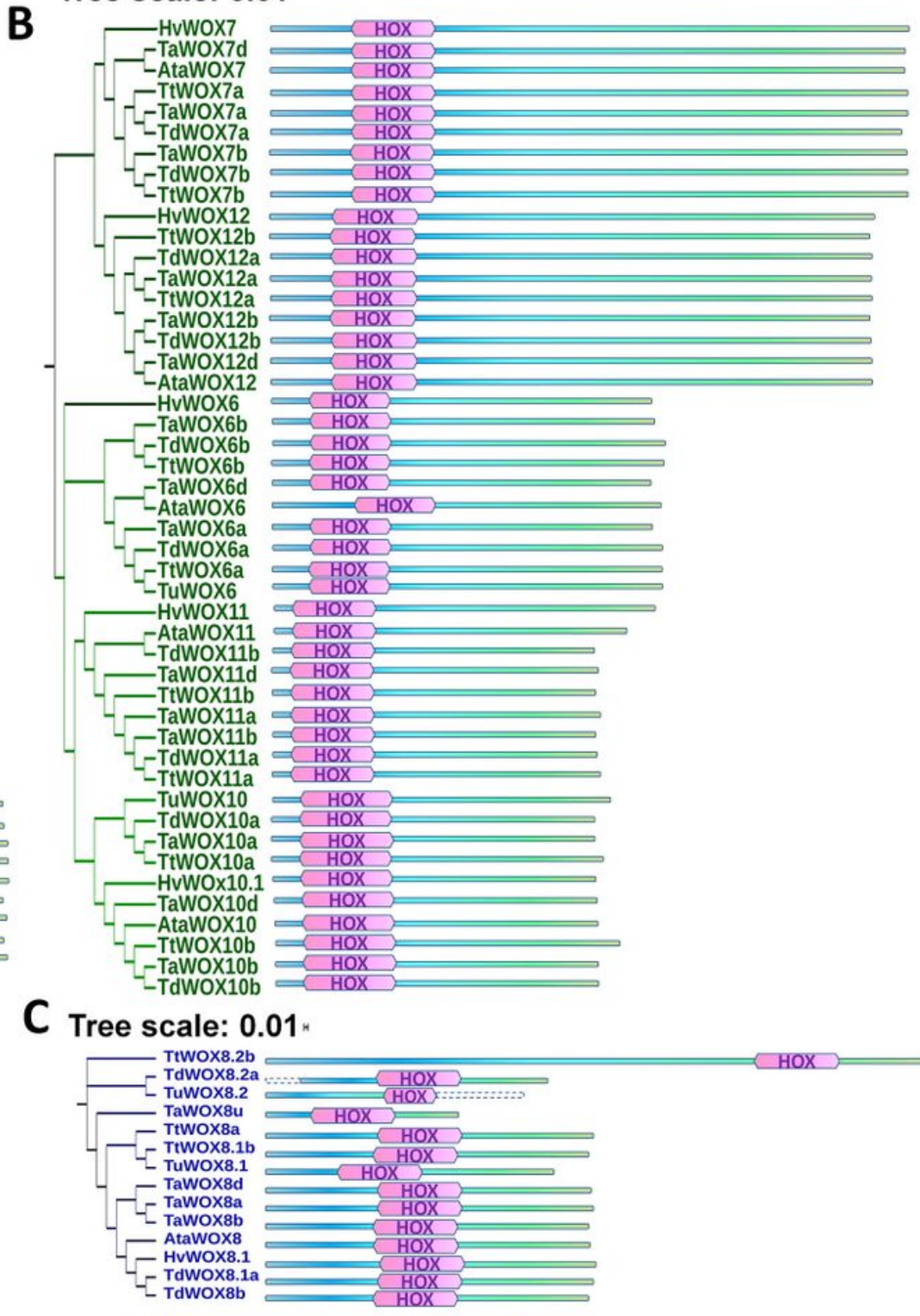

Figure 6

Depiction of the domain structure of WOX proteins in six Triticeae species. Positions of HOX homeodomain, WUS-Box motif and EAR domain in WOX protein of the six Triticeae species including wheat, barley, T. dicoccoides, T. turgidum, A. tauschii, and T. urartu. WOX members were divided by their phylogenetic relationship. There were HOX homeodomain, WUS-Box motif and EAR domain in WUS clade WOX proteins in the six Triticeae species (A). Positions of HOX homeodomain in intermediate clade WOX proteins in the six Triticeae species (B). Positions of HOX homeodomain in ancient clade WOX proteins in the six Triticeae species (C). Length of WOX members were displayed by the bar length, positions of HOX homeodomain were displayed as pink hexagon, WUS-Box motif was displayed as green round dot, and EAR domain was displayed as blue round dot. 
A

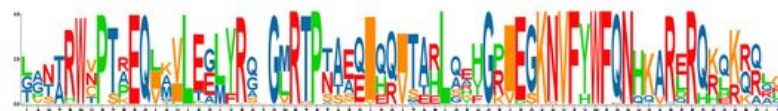

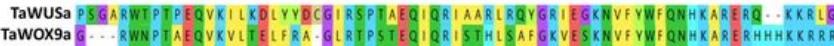

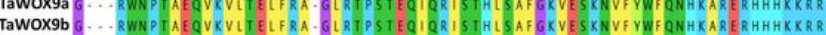
TaWOX9d G...RWNPTAEQVKVITELIRA. GLRTPSTEQIQRISTHLSAFGKVESKNVF YWF QNHKARERHHHXXRR HVWOX9 -...RWNPTAEQVKVLIELLRA. GLRTPSTEQIQRISTHLSAL GXVESKNVFYWFNHKARERHHHKRRR AtaWOX9 6 ....RWNPTAEQVKVLTELIFRA. GLRTPSTEQIQR I STHLSAFGKVESKNVFWWFNHKARERHHHKKRRR TaWOX9a G...RWNPTAE QVKVLTELLFA-GLRTPSTEQIQR IS THLS AFGKVESKNVF YWF QNHKARERHHHKKRR TOWOX9b G...RWNPTAEQVKVLTELFRA-GLRTPSTEQIQR I STHLSAFGKVESKNVFYWFQNHKARERHHHKKRR TEWOX9a -...RWNPTAE QVKVLITELFRA. GLRTPSTEQI QRISTHLLAF GKVESKNVF YWF QNHKARERHHHKKRR TTWOX9b - - RWNP TAEQVRVLITELFRA- GLRTPSTEQIQRISTHLSAF GKVESXNVFYWFQNHKARERHHHKXRR W TaWOX2a TGTTRWCPTPEQLMILEEMYRG. GLRTPNASQI QQI TAHLAHYGRIEGKNVYWF QNHKARDRQKLRRRLC

Hewox

AtaWox 2

TdWOX2

TdWOX2b

TtWOX2a

TuWOX2

TaWOX3a

TaWOX3d
HvWOX3

HvWOX 3
AtaWOX 3

Tdwox

TdWOX3b

TtWoX3b

TaWox

TaWOX $4 \mathrm{~b}$

HvWOX4

AtaWOX4

TdWOX4a

Ttwox4a

TtWOX4b

TuWOX4 GITRWNPSAEQI XVLEALYR

TaWOX5O A ARWP SAEQ I XVL EAL

TaWOXSb LANARWT P TKEQVSVLL GL

Tawoxsd

HVWOX5 AGNARWT PT

AVWOXS A GNARWT P I KEQ Q GVLE GL

TdWOXSa LANARWTPT KEQ

TdWOXSb LANARWT PTKEQVUGVLEGLY

TtWOXSa LANARWT PTKEQVSVLEG

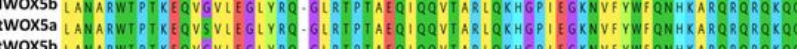

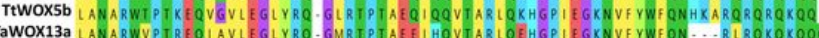

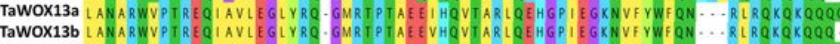

TaWOX13d LANARWVPTRQQIAVLEGLYRQ. GMRTPTAEEI HQVTARLQEHGPIEGKNVFYWFQN . . RLRQKQKQQQ

HVWOX13 LANARWVPTREQIAVLDGLYRQ. GMRTPTADEIHQVTARLQEHGPIEGKNVFYWFQN...RLRQKQRQQR

AtaWOX13 LANACWVPTREQIIIVLEGLYRQ. GMRTPTAEE I HQVTARLQEHGPIEGXNVFYWEN - . RLRQRQRQQQC

TdWOX13a LANARWVPTREQIAVLEGLYRQ. GMRTP TAE EI HQVTARLQEHGPIEGKNVFYWFQN -...GLRQKQKQQQQ

TdWOX13b LANARWVPTREQIAVLE GLYRQ. GMRTPTAE EVHQVTARLQEHGP I EKNVFYWF QN - . RLRQRQKQQQ.

TTWOX13a LANARWVPTREQIAVL EGLYRQ. GMRTP TAE EI HQVTARLQEHGPIE GKNVFYWF QN - . RLRQRQKQQQS

TTWOX13b LANARWVPIREQIAVLEGLYRQ. GMRTP TAEEVHQVTARLQEHGP I EKNVFWWRN - . RLRQKQKQQQ.

TuWox13

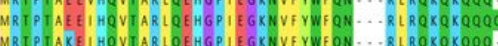

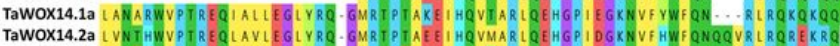

TaWOX14b LVNARWVPTREQLAVLEGLYRQ. GMRTPAAEEI HQVITARLQEHGPI EXNVFHWFQNQQVRLRQREKQQ

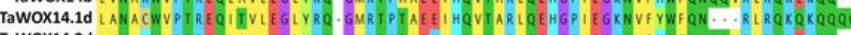

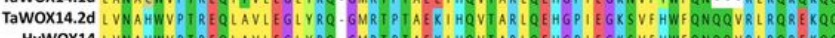

HVWOX14 IVNAHWVP TREQLAVLEGLYRQ. GMRTP TAEXI HQVI ARLQRHGPI EKSVF HWF QNQQVRL LRQREKQ

AtaWOX14.....RWVPTREQLAVLDGLYRQ. GMRTP IAE EI HQVTARLQEHGPI G GNVF HWF QNQMVQLRQMERQ

TdWOX14a IVNARWVP IREQLAVLEGLYRQ. GMRTPAAE EI HQVIARLQE EGPI GXNVF HWFQNQQVRLRQREKQO

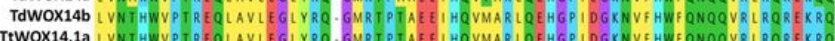

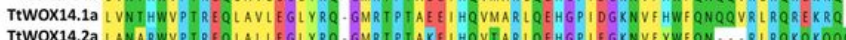

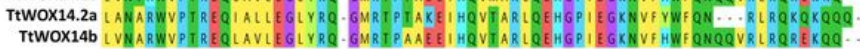

B

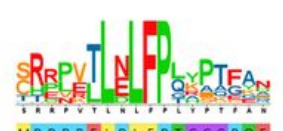

MPPPRELPLFPTGGGRQE

TREVETLELFPLKAACYD

TREVETLELFPLKAA-Y
TREVETLELFPIKAACY

TREVETLELFPLKAA-Y
TREVETLELFPLKAACY

REVETLELFPLKAACY

REVETLELFPLKAACY

REVETLELFPLKAA-Y

CRPLKTLDLFPGALKE

CRPLKTLDLFPGAIKEE

CRPLKTLDLFPGAIKEEH

VR-LQTLDLFPGAIKEE

CRPLKTIDLFPGATKEE

CRPLKTLDLFPGAIKEE

CRPLKTLDLFPGAIKEEQ
CRPLKTLDLFPGAIKEEO

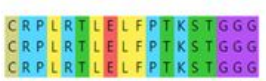

CRPLRTLELFPTKSTGGO

CRPLRTLELFPTKSTI
CRPLRTLELFPTKST

CRPLRT

CRPLRTLELFPIKSTG

CTENVTLELFPLRPQGKA

CTDNVTL LFPLRPQGKA

TONVTLELFPLRPQGKA

TDNVTLELFPLRPQGKA
TENVTLELFLLPOGKA

TIDNVTLELFPLRPQGKA

CTENVTLELFPLRPQGKA
CTDNVTLELPLRPOGKA

SRRPETLNLFPLHPTEAI

SRPETLNLFPLHPTEAI

RRPETLNLFPLHPTFAI

PRPETLNLFPLHPTFAI

RRPETLNLFPLHPTEAL

RRPETLNLFPLHPTFAL

SRRPETLNLFPLHPTFAI

RRPETLNLFPLHPTFAL.

RRPVLLNLFPQYPTFAN

RRPVLLNLFPQYPTFAN
RRPVLINLFPOYPTFAN

RRPVLLNLFPQYPTFGN

RRPVLLNLFPQYPTFAN

HRPVLLNLFPQYPTFAN

SRPVLLNLFPQYPTFAN

SRPYLNLFPQYPTFAN

RRPVLLNLFPQYPTFAN

RRPVLLNLFPQYPTFAN

SHRPVLLNLFPQYPSFAN

HSPVLLNLFPQYPTFAN

SHRPLLNLFPQYPTFAN
HRPVLINLFPOYPTFA

SHRPVLLNLFPQYPTFA

SNRPVLLNLFPQYPTFAN

SHRPVLLNLFPQYPTFAN

SHSPVLLNLFPQYPTFAN

SHRPVLLNLFPQYPTFAN

SHSPVLLNLFPQYPTFAN
SHRPYLLNLFPYPSFAN

SHRPVLLNLFPQYPSFAN
SHRPVLLNLFPQYPTFAN
C

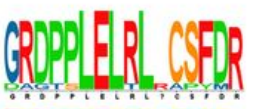

\section{AGTSLELTLRAPYM.}

GRDPPLELRL-CSFDR

GRDPPLELRL-CSFDR

GRDPPLELRL. CSFDR

GRDPPLELRL-CSFDR

GRDPPLELRL-CSFDR

GRDPPLELRL. CSFDR

GRDPPLELRL - CSFDR

GRDPPLELRL. CSFDR 


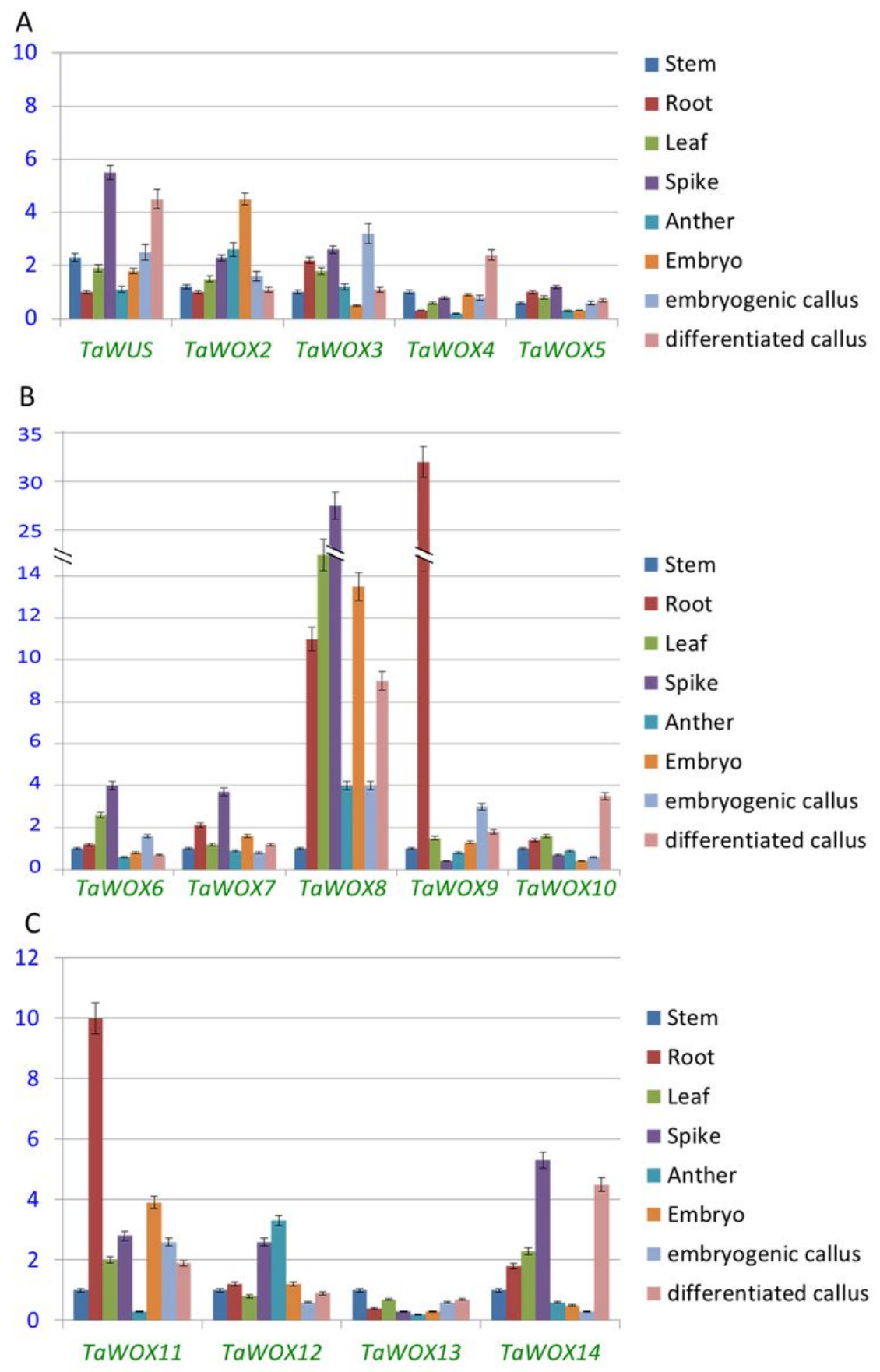

Figure 8

Expression pattern of TaWOX genes in various tissues of wheat. Gene expression level was examined using qPCR. The qPCR data was normalized using wheat TaActin gene. Values were means \pm sd of three biological replicates.

\section{Supplementary Files}

This is a list of supplementary files associated with this preprint. Click to download.

- Additionalfile2.docx

- Additionalfile96.docx 